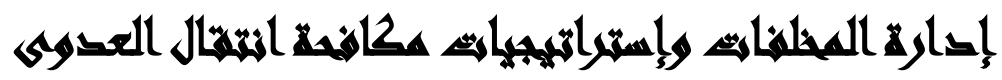

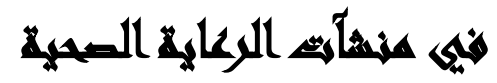

\author{
مجد متبولي عطية غريب(')- جمال محمد عطية الخولي(")

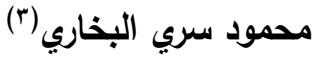

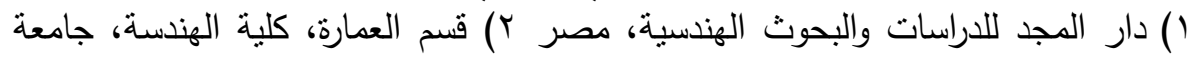
عين شمسب) قسم العلوم البيئية الطبية، كلية الدراسات العليا والبحوث البيئة، جامعة عين شمس شمس

\section{المستخلتص}

يعالج البحث مشكلة التعامل مع المخلفات الصلبة والسائلة والغازية بنوعيها العادية

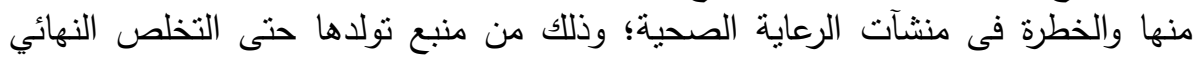

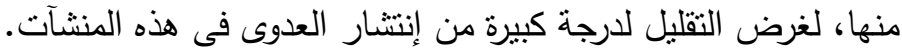

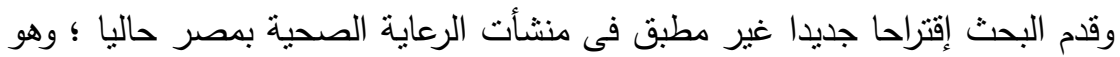

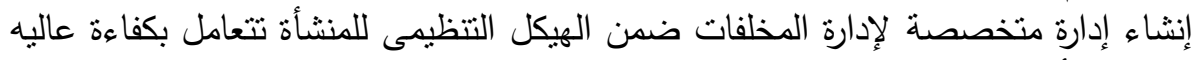

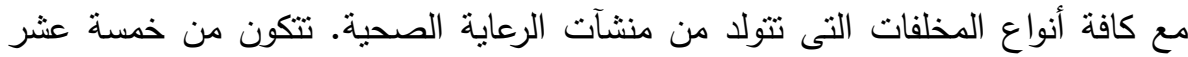

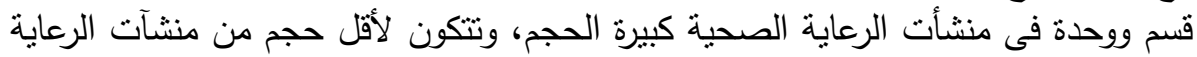

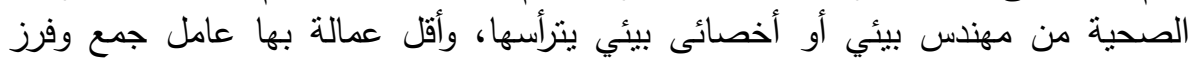

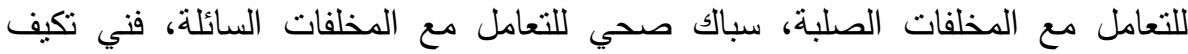
ل اللتعامل مع المخلفات الغازية.

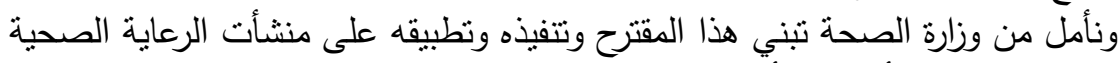

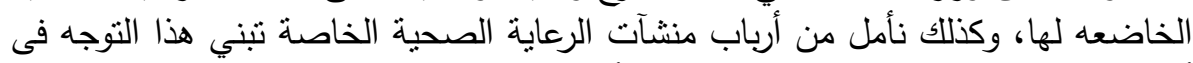

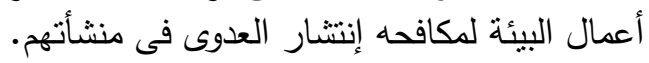

\section{Xanall}

يستعرض البحث بعض من الدراسات المرجعية للمخلفات الصلبة والسائلة والغازية فى

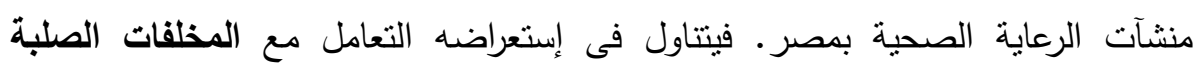

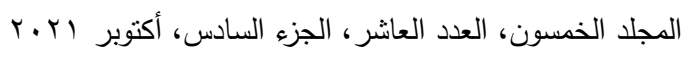

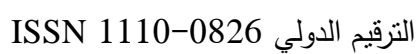

$$
\begin{aligned}
& \text { التزقيم الدولي الموحد الإلكتروني 3178-2636 لنربم }
\end{aligned}
$$


العادية - المخلفات غير الخطرة (شبه منزلية) - والمخلفات الصلبة الخطرة المتولدة من الرعاية الصحية، وكمية كل منها، ومراحل تداولها من مصدر نولدها حتى تخزينها فى متى فئه

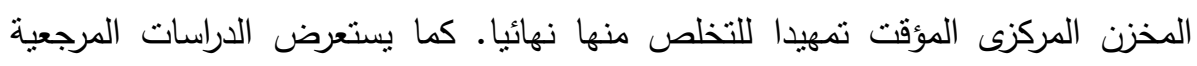

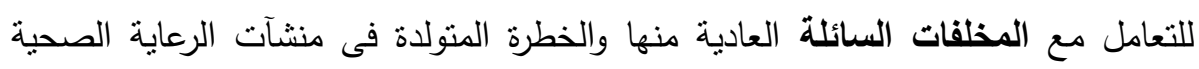

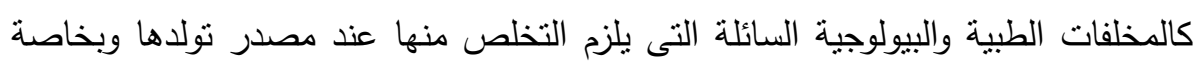

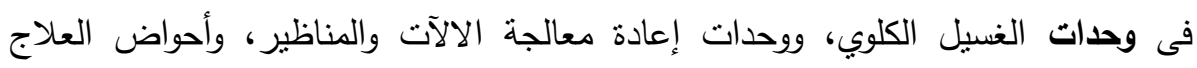
الطبيعي، وغير ذللك. وكذلك بستعرض بعض الدراسات المرجعية لآلية التعامل مع المخلفات الغازية ومنطلبات التهوية وطرد الأبخرة والغازات خارج منشأة الرعاية الصحية.

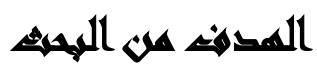

يهدف البحث إلى وضع معايير وأسس لإدارة المخلفات بكافة أنواعها المتولدة من منشأة للرعاية الصحية. وأهمية البحث أنه مع التطور الحادث في أعمال الحفاظ على البيئة، فإن البحث يقترح

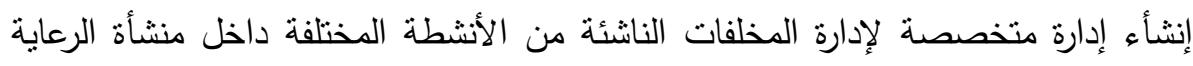

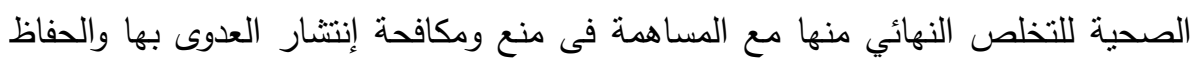
على بيئة نظيفة داخل المنشأة وخارجها.

\section{منهمج المهيد}

منهج البحث المستخدم؛ استخدم المنهج الوصفى فى وصف الآليه المنبعة فى

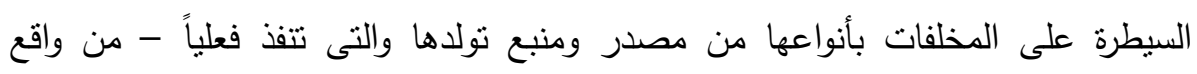
الزيارات الميدانية والعملية - فى عدد من منشآت الرعاية الصحية موضع هذه الدراسة. وكذلك استخدم المنهج التطبيقي؛ حين اجريت الزيارات الميدانية لعدد من المستشفيات وصمدت لها إستبيانات (Questionnaires) تستهدف آراء المديرين ورؤساء الأقسام 600

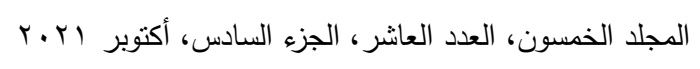

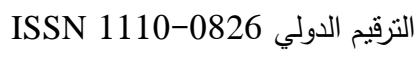

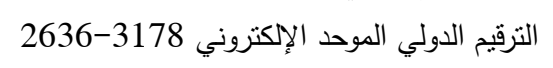


المعنية بهذه الدراسة، ومن خلال ما أبدوه من آراء ووجهات نظر من واقع خبراتهم العلمية

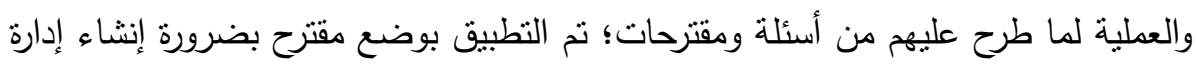

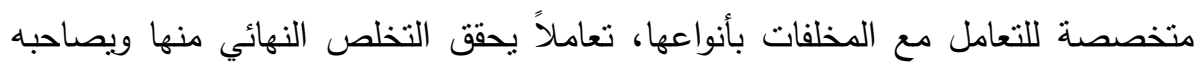
منع لإنتشار العدوى بها.

\section{محتري اللهيث}

\section{التعامل مع المخلفات فى منشآت الرعاية الصحية:}

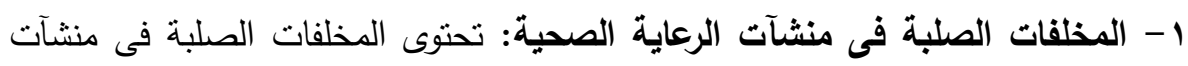

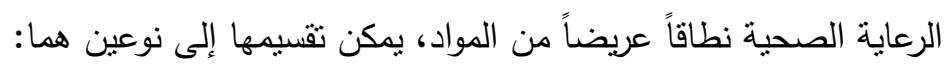

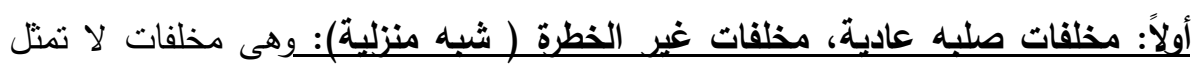

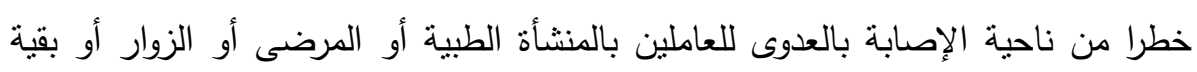

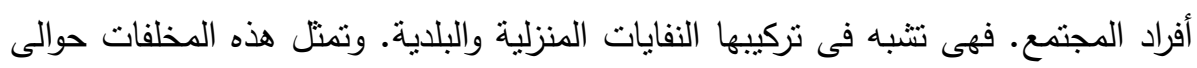
\%1\% من مخلفات المنشآت الصحية (وزارة الصحة والسكان-دليل مكافحة العدوى،

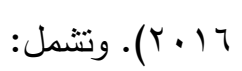

مواد التعبئة والتثلبف: منل صناديق كرتون، أكياس ورقية، أكياس بلاستيك، مواد تغليف السرنجات والأبر والسنون وأجهزة الوريد، ... الخ. أوراق تغليف المعدات والمستلزمات الطبية

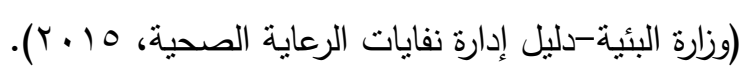

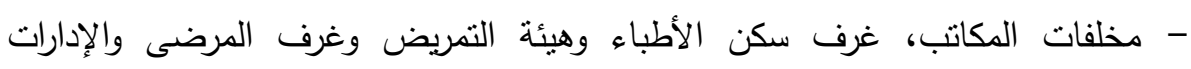

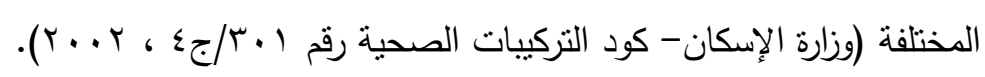

- مخلفات المطبخ وبقايا طعام المرضى: وهى نفايات عضوية مرنبطة بالطعام (وزارة

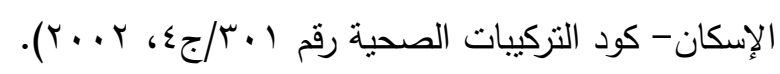

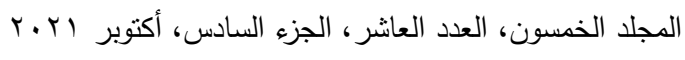

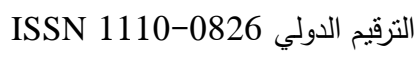

$$
\begin{aligned}
& \text { الترقيم الدولي الموحد الإلكتروني 3178-2636 }
\end{aligned}
$$


- نفايات الورق والصناديق ومواد التغليف المختلفة والزجاجات والأواني البلاستيكية والمناديل والفضلات وغير ذلك من المواد التى لم تتلوث بسوائل الجسم. حيث تقصل هذه النفايات من المنبع والتعامل معها يكون بمثل التعامل مع النفايات الصلبة المنزلية.

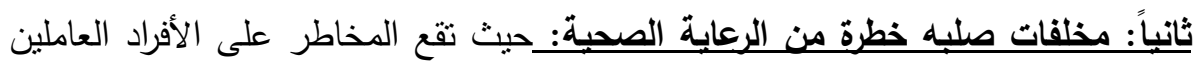
بالمستشفى، وخاصة المتعاملين مباشرة مع النفايات بالإضافة إلى المرضى والمترددين.

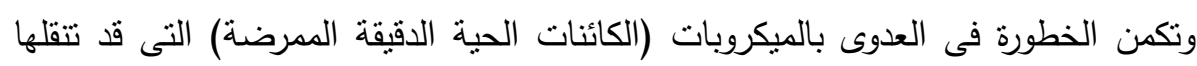
هذه النفايات إليهم. والمخاطر قد تقع على بيئة المستتفى سواء داخلها أو خارجها. فالتخلص من هذه النفايات بدون معالجة فى مقالب سيئة الإدارة والتصميم تجعل العناصر

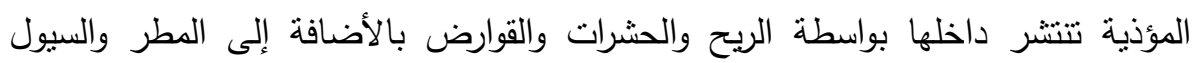
المحتملة أو عصارة النفايات التى قد تتخلل التربة فى طريقها الى المياه الجوفية. وتتكل المخلفات الصلبة الخطرة ه1\% من المخلفات الصلبة فى منشأة الرعاية الصحية. وتنشمل :

1 - المخلفات المعلية: وتتشنمل المخلفات المعدية على جميع الأشياء التى تحتوى على

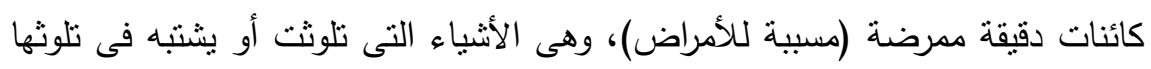

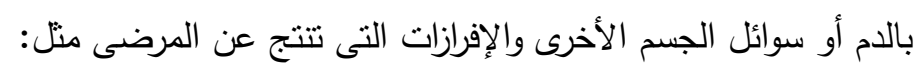

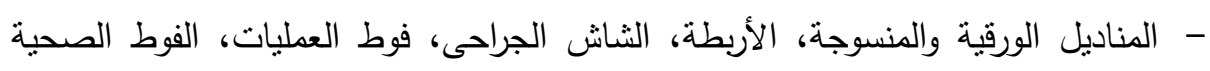

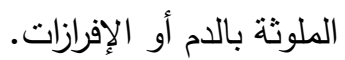

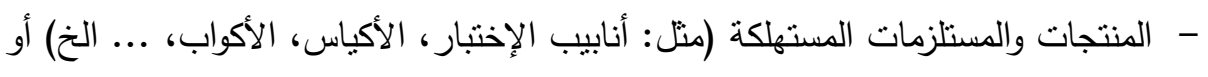

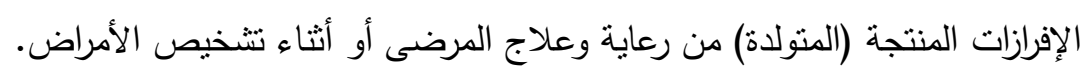

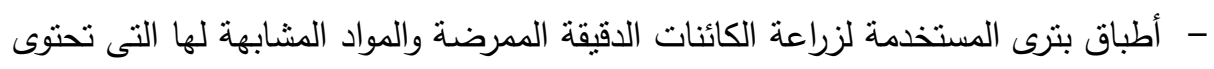
على بكتريا حية أو فيروسات أو فطريات. 
- القفازات والقساطر المستعملة ومزارع ومخزونات الجراثيم المعدية ومخلفات الرعاية الصحية من وحدات الغسيل الكلوى والأسنان ومخلفات وحدات عزل المرضى والمخلفات الملوثة بالدم أو مشتقاته والعينات التشخيصية المستهلكة وحيوانات التجارب المعملية

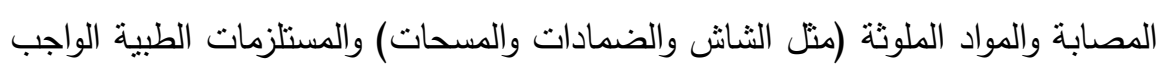
التخلص منها منل أجهزة الوريد.

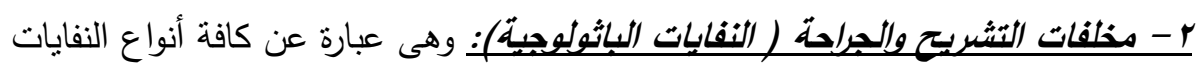
التى تتتج عن فصل أو بتر أو قطع أحد أجزاء الجسم، منل: المشيمة، الأورام

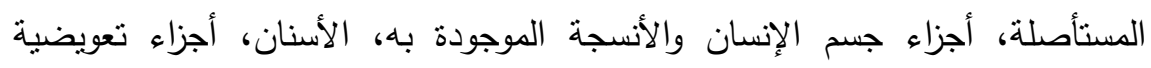
مزروعة، ومخلفات معامل الباثولوجيا وأجسام الحيوانات.

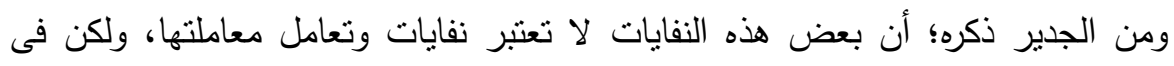
أحوال كثيرة يجرى دفنها فى المقابر (على إعنبار أنها جزء من جسم الإنسان).

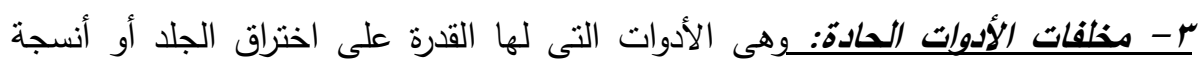

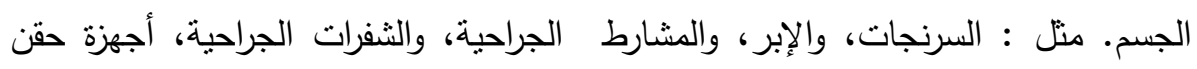

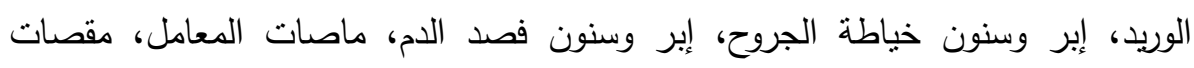

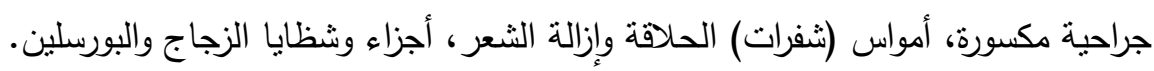

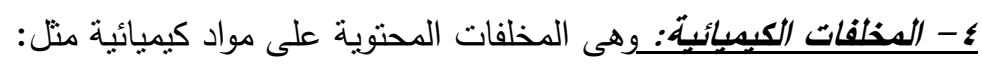
أ- مخلفات المعدل: المواد المستخدمة داخل المعمل والزجاجات الفارغة للمواد الكيماوية

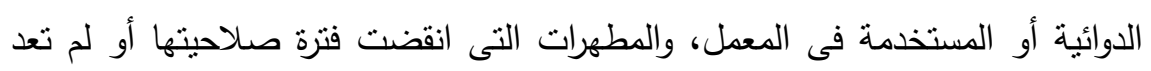
هناك حاجة إليها، والمواد المستخدمة فى التتخيص والمواد السامة والمسببة للتآكل

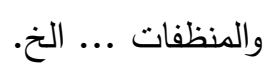

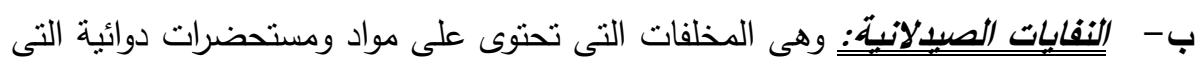

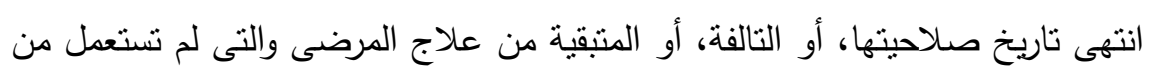

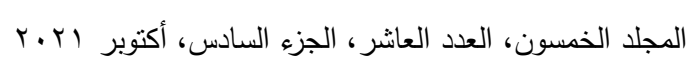

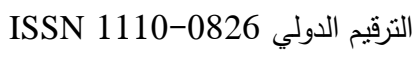

$$
\text { الترقيم الدولي الموحد الإلكتروني 3178-2636 التروب }
$$


قبل، او التى يتم لفظها من المرضى، أو التى تعاد لعدم الحاجة اليها، واللقاحات

$$
\text { والأمصال التى انقضت فترة صلاحيتها. }
$$

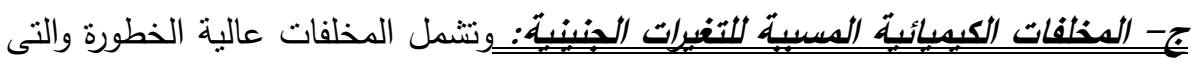
تسبب طفرة وراثية أو تتوه وراثى أو سرطان، وتحتوى عادة على مواد ذات خواص سامة للجينات. ومن أمثلتها: العقاقير المستخدمة لعلاج السرطان وبعض ولته المواد الكيماوية.

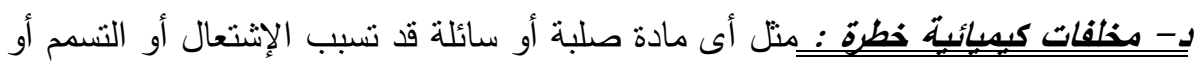
التأكل أو الحساسية أو الإلتهاب أو التفاعل أو كونها مسرطنة أو مشوهة أو مسببة للفقرات الوراثية. وكذلك المطهرات التى انقضت فترة صلاحيتها أو لم تعد هناك حاجة إليها، والمنظفات...

هـ المواد الكبيبائبة المثبطة للذلايا: والتى تدخل ضمن تركيب العلاج الكيميائي للأورام.

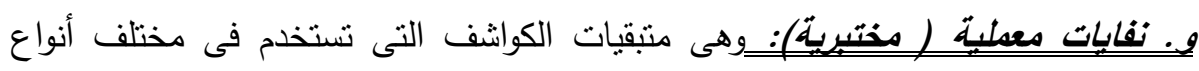
التحاليل وحفظ وصباغة العينات. ه- -نفابيات العبولت المعبأة تحت ضغط: منل عبوات الأيروسولات بمختلف أنواعها، وقد تسبب الإنفجار أو الإثتعال أو التسمم. I - المولد المشعة: وهى نفايات صلبة أو سائلة أو غازية ملوثة بالنويدات (النيوكليدات)

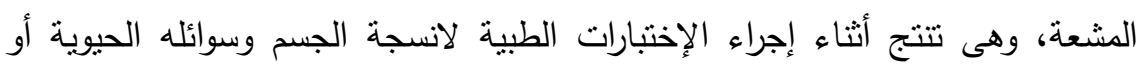
نتيجة لتصوير أعضاء أو أجهزة الجسم بالأشعة، أو بسبب إجراءات الأبارت تحديد مواضع الأورام أو تشتخدم كعلاج إثعاعي لبعض الأمراض.

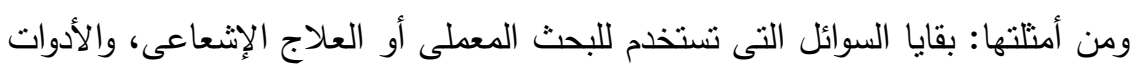

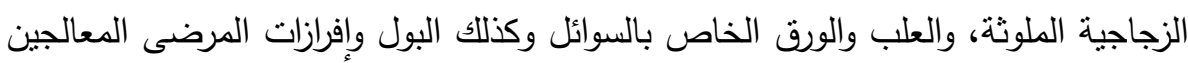
بمواد إنعاعية، أو الذين أجريت لهم اختبارات تشخيصية باستخدام هذه المواد. 
وتلكك مسئولية هيئة الطاقة النووية أو إدارة الوقاية من الإشعاع بوزارة الصحة بالتسيق مع

$$
\text { المنشأت الصحية حسب صنف النفاية المشعة. }
$$

v- المعادن الثقبلة: وتشمل مخلفات المواد والأجهزة التى تدخل فيها المعادن التقبلة أو

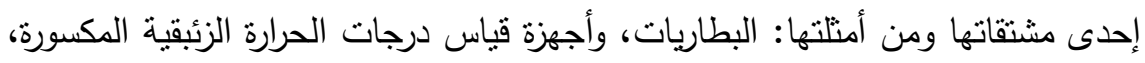
واجهزة قياس ضغط الدم الزئبقية (وزارة البيئة، الدليل الإرشادى لإدارة نفايات لئنات الرعاية

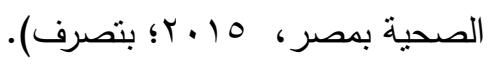

\section{1- 1 كمية المخلفات الصلبة فى منشأت الرعاية الصحية بمصر :}

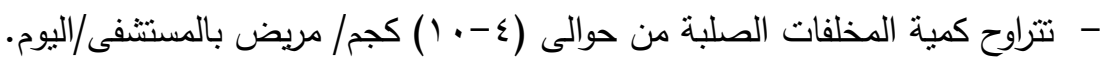

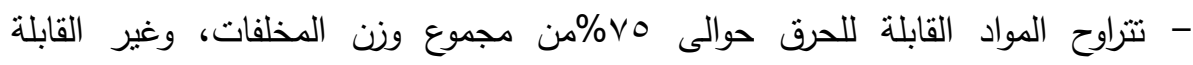

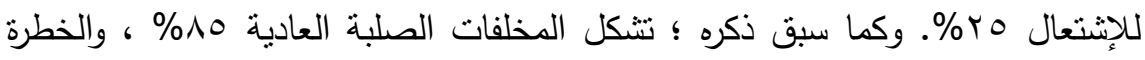

$$
\% 10
$$

والجدول التالى (1) يوضح افتراضات لمعدل نوّلد النفايات الخطرة من مختلف الأنشطة الطبية للمنشأة الصحية ، بناء على الخبرة المكتسبة من عدد من المشروعات

\begin{tabular}{|c|c|}
\hline كجم / يوم & معدل تولا النفايات الخطرة \\
\hline $.6 Y \vee 0$ & لللسرير في المستشفيات التى بها أسرة. \\
\hline$r_{6} \ldots$ & لماكينة الغسيل الكلوى.(تعمل وردينين كل يوم). \\
\hline $.6 \wedge$ & للوحدات الصحية والمراكز الصحية وجميع المنشآت غير المحتوية على أسرة \\
\hline $.6 \varepsilon$ & للعيادات فئة ا وتثشمل: الجراحة، والنساء، والأسنان، والجلدية، والمعامل. \\
\hline $.6 \mathrm{Y}$ & للعيادات فئة ب وتثمل: باقى أصناف العيادات. \\
\hline .61 & للصنيدليات \\
\hline & - المصدر : وزارة البيئة - إدارة نفاي \\
\hline
\end{tabular}

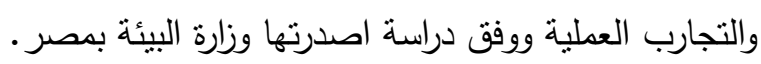

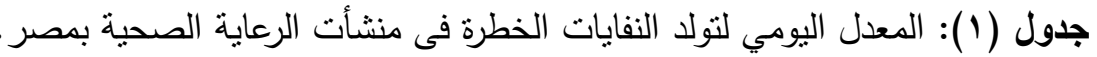

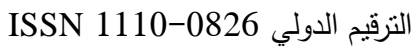

الترقيم الدولي الموحد الإكتروني 3178-2636 
ا ب- ت تداول نفايات الرعاية الصحية الصلبة ذات الخطورة داخل منثأة الرعاية الصحية.

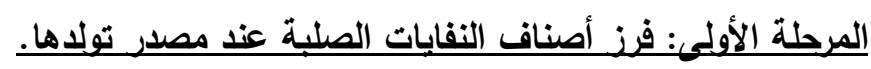

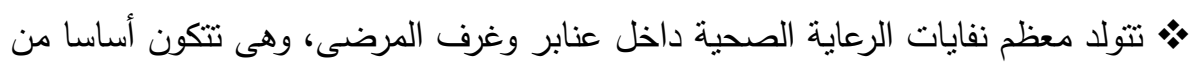
النفايات شبه المنزلية (البلاية) والنفايات المعدية والسنون والأدوات الحادة والئات والنفايات الكيمائية.

• إن أبسط الطرق لضمان فرز هذه الأصناف هو إنثاء واستعمال نظام جمعها فى الطي

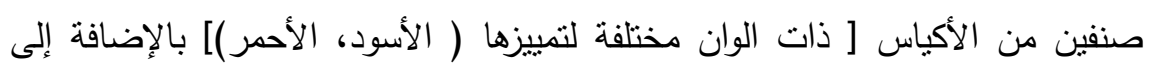

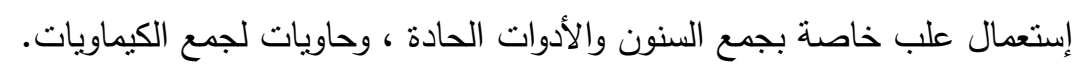

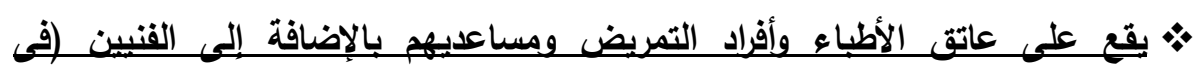
المعامل/المختبرات) القيام بفزن النفابات غند مواضع تولدها.

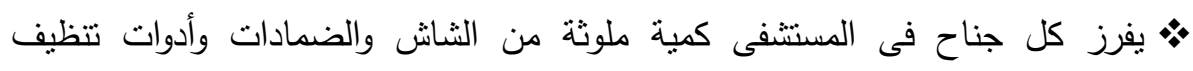

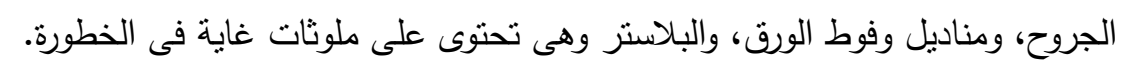

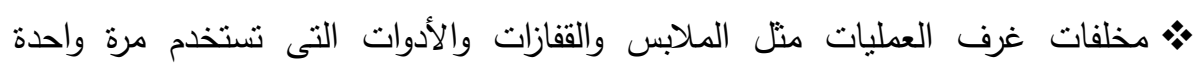

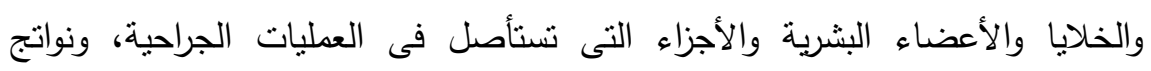
عمليات الولادة تثنل خطورة شديدة على الصحة العامة حالة عدم جمعها بطريقة آمنة.

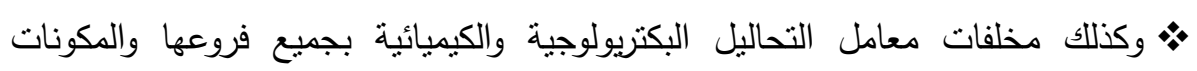

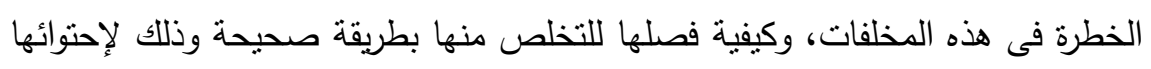

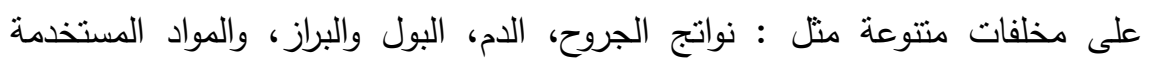

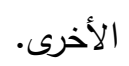

يبين الجدول(r) طرق من فرز وتجميع النفايات الصحية الصلبة الخطرة عند الدنبع، منعاً

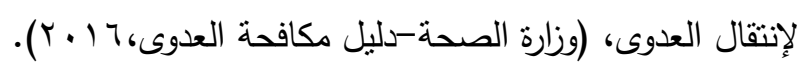

606

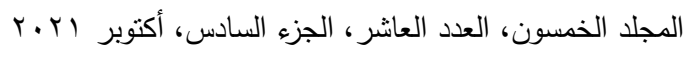

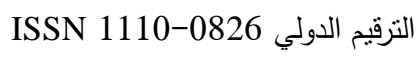

$$
\begin{aligned}
& \text { الترقيم الدولي الموحد الإلكتروني 3178-2636 }
\end{aligned}
$$




$$
\text { مجلة العلوم البيئية }
$$

كلية الدراسات العليا والبحوث البيئية - جامعة عين شمس البئه

مجد منبولي عطية غريب وآخرون

جدول(ץ): طرق فرز وتجميع النفايات الصحية الصلبة الخطرة عند المنبع (أى السيطرة عليها عند

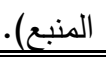

\begin{tabular}{|c|c|c|c|}
\hline ملاحظات & طرق فرز وتجميع النفاية الصلبة الذطرة عند المنبع & نفايات الرعاية & م \\
\hline \multirow[t]{2}{*}{ تالجنب العادة تغطية } & 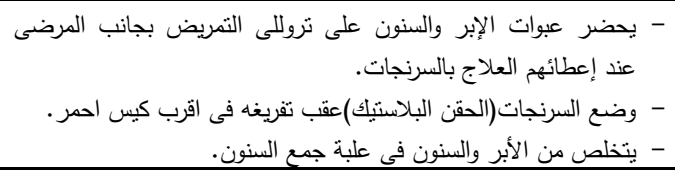 & السرنجات & 1 \\
\hline & - - - يعقدة أمانع غيارات الجروح الملوثة في أكياس حمراء صغيرة، وغلق الكيس & 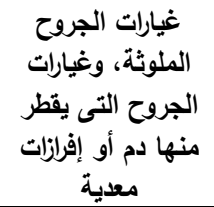 & r \\
\hline \multirow[t]{4}{*}{ 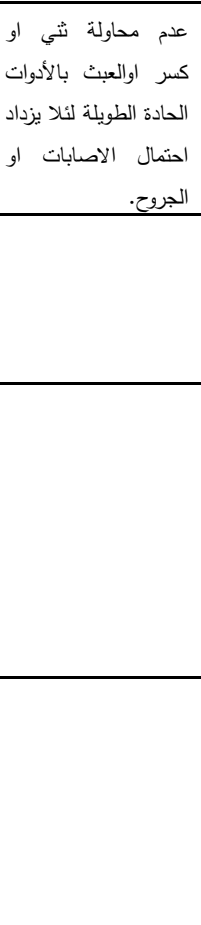 } & 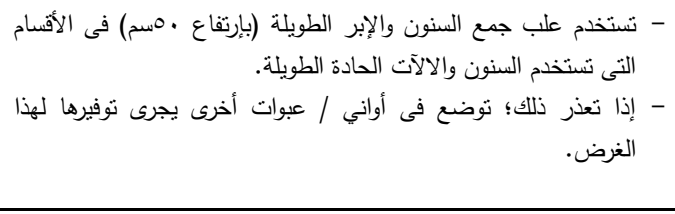 & 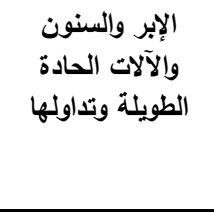 & $r$ \\
\hline & 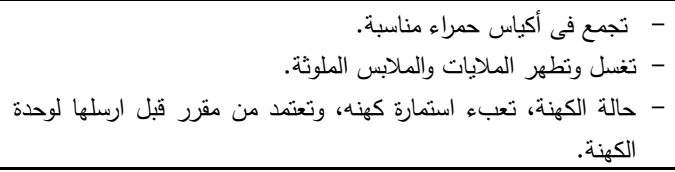 & ملايات ويباضات & $\varepsilon$ \\
\hline & 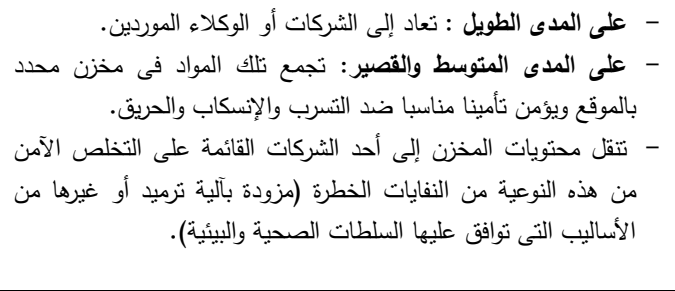 & 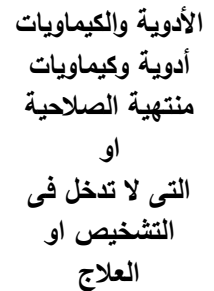 & ○ \\
\hline & 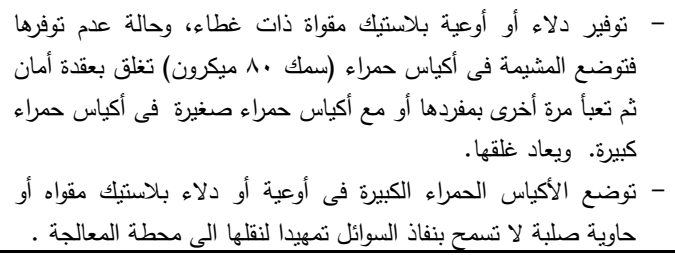 & تداول المشيمة & 7 \\
\hline
\end{tabular}

المجلد الخمسون، العدد العاشر ، الجزء السادس، أكتوبر ابr.r.

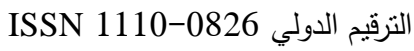

الترقيم الدولي الموحد الإكتروني 3178-2636 


$$
\text { مجلة العلوم البيئية }
$$

كلية الدراسات العليا والبحوث البيئية - جامعة عين شمس لئه

مجد منبولي عطية غريب وآخرون

\begin{tabular}{|c|c|c|c|}
\hline & - تغسل الحاويات داخل وحدة معالجة النفايات ثم تعاد إلى القسم. & & \\
\hline & & \multicolumn{2}{|c|}{ تابع جدول(r): } \\
\hline & 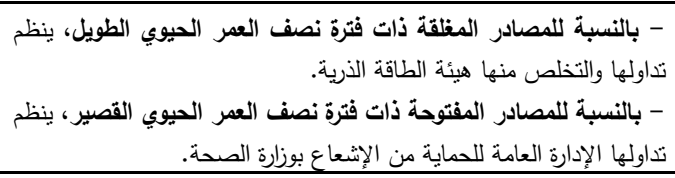 & 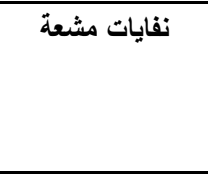 & $\mathrm{v}$ \\
\hline & 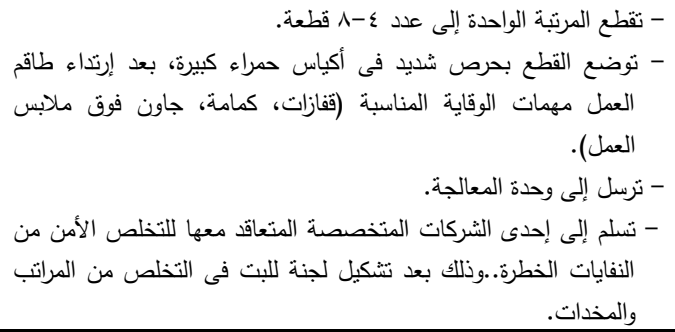 & (المخدات) الملوثة. & $\wedge$ \\
\hline & 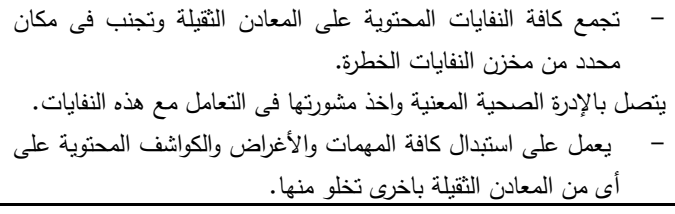 & 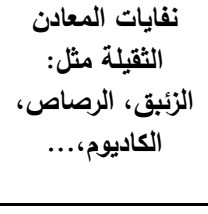 & 9 \\
\hline & 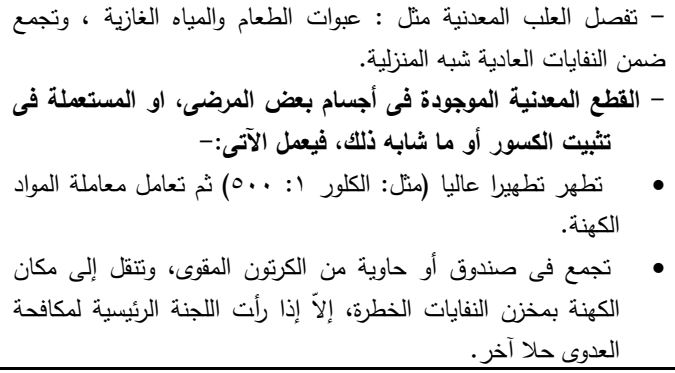 & 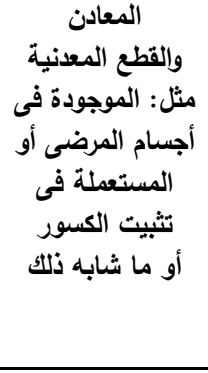 & 1 . \\
\hline الأكزاء & 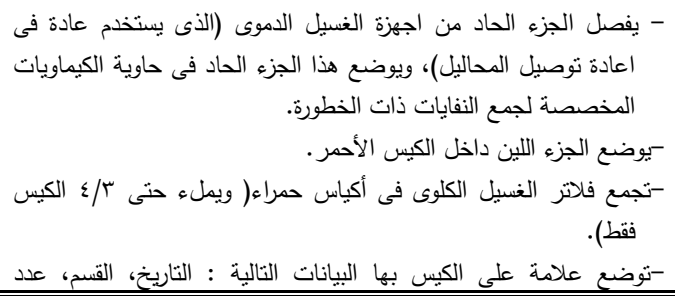 & الاجهوى وفلاتريل & 11 \\
\hline
\end{tabular}

608

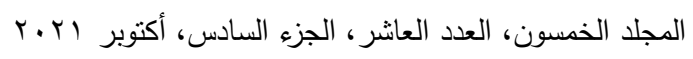

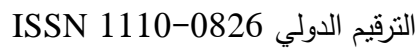

$$
\text { الترقيم الدولي الموحد الإكتروني 3178-2636 }
$$


مجلة العلوم البيئية

كلية الدراسات العليا والبحوث البيئية - جامعة عين شمس لئلة

مجد منبولي عطية غريب وآخرون

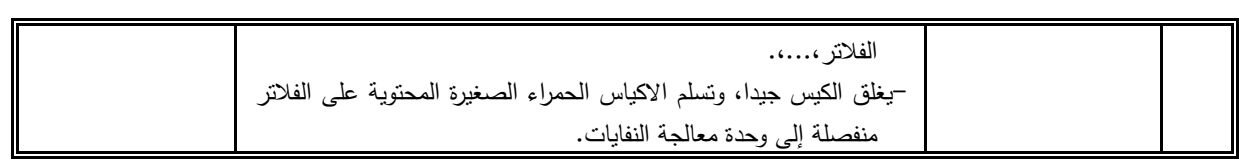

تابع جدول(r)

\begin{tabular}{|c|c|c|c|}
\hline 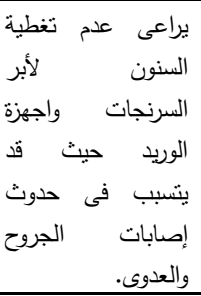 & 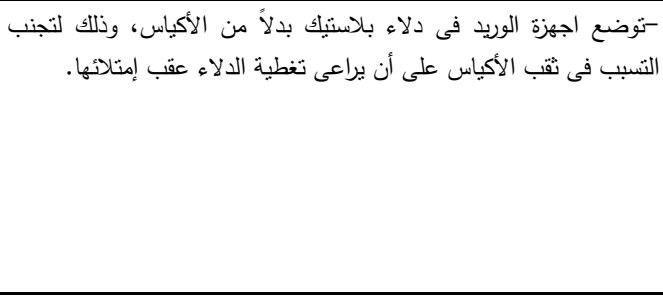 & اجهزة حقن الوريد & Ir \\
\hline 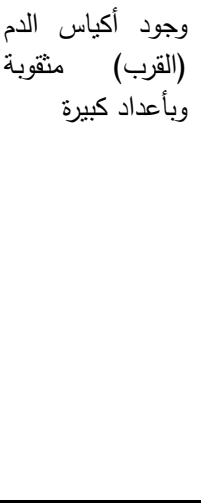 & 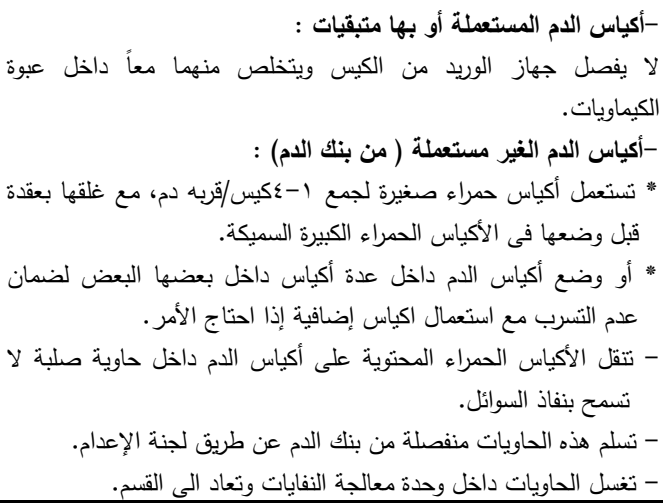 & اكياس الام & ir \\
\hline 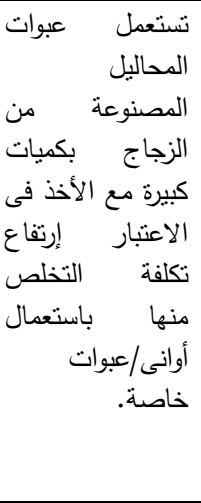 & 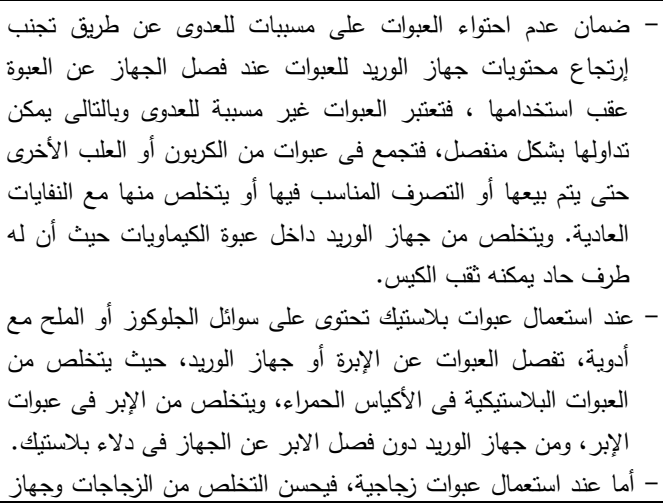 & عبوات المحاليل. & $1 \varepsilon$ \\
\hline
\end{tabular}

المجلد الخمسون، العدد العاشر ، الجزء السادس، أكتوبر اب.r.

الترقيم الدولي 0826-0 التئ

الترقيم الدولي الموحد الإكتروني 3178-2636 


\begin{tabular}{|c|c|}
\hline & حدوث جروح قطعية أو إصابات أخرى. الدياك خوفا من تكسر الزجاج وتسبيه فى \\
\hline
\end{tabular}

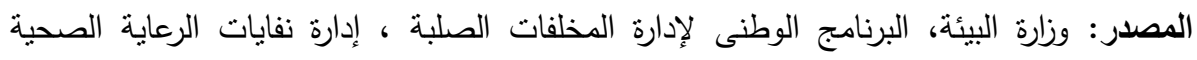

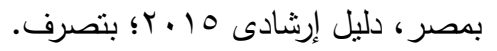

$$
\begin{aligned}
& \text { المرحلة الثانبة : جمع النفابات عقب فزها: }
\end{aligned}
$$

•• إذا احتوت أكياس جمع النفايات المنزلية أو شبه المنزلية على كميات - ولو صغيرة -

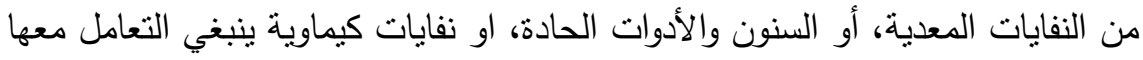

$$
\text { على أنها نفايات خطرة. }
$$

• ثوجد النفايات الكيمائية بكميات كبيرة فى أقسام معينة مثل المعامل، فينبغي حفظ هذه

$$
\text { النفايات منفصلة عن أصناف النفايات الأخرى فى أوعية خاصة. }
$$

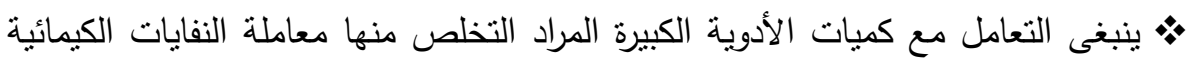
سواء بسواء. اما الأدوية ذات الكميات الصغيرة نسبيا فيمكن التخلص منها مع النفايات

$$
\text { المعدية. }
$$

•• إذا كانت طريقة المعالجة المتوفرة هى الترميد؛ فتعامل النفايات الكيمائية بنفس طريق

$$
\text { التعامل مع النفايات المعدية والسنون والأدوات الحادة. }
$$

• أما إذا كانت طريقة المعالجة المتوفرة هى التعقيم، فينبغي جمع أواني النفايات الكيمائية ومعالجتها بشكل منفصل بأى وسيلة من الوسائل الفيزيائية أو الحرارية أو بالتعادل.

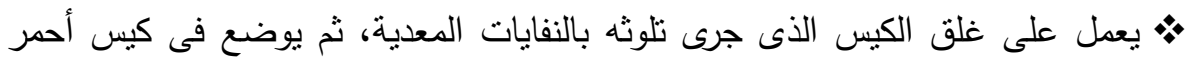

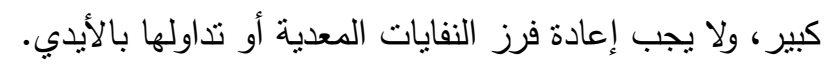

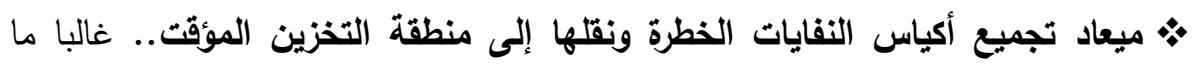

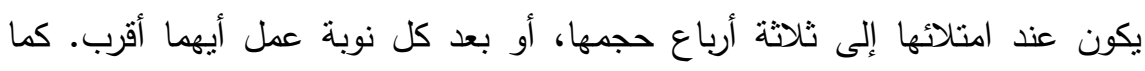
يتعين التخلص من صناديق المخلفات الحادة عند امتلائها إلى ثلاثة أرباع حجمها.

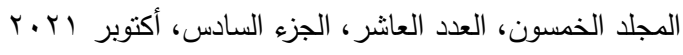

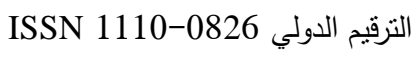

$$
\begin{aligned}
& \text { الترقيم الدولي الموحد الإلكتروني 3178-2636-26 }
\end{aligned}
$$


المرحلة الثالثة: نقل نفابات الرعابة الصحية داخل المستشفى: تنقل النفايات من أماكن تولدها إلى المخزن الوسيط أو المؤقت (بكل قسم أو طابق)، ثم تنقل منه إلى محطة

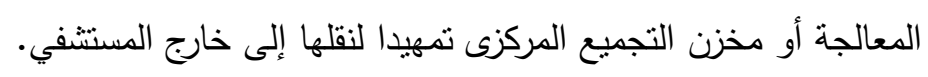

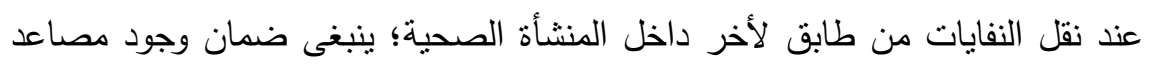

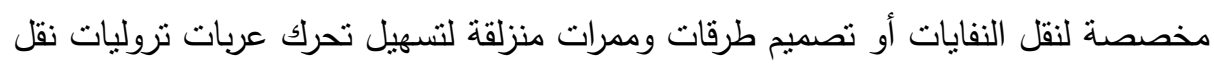

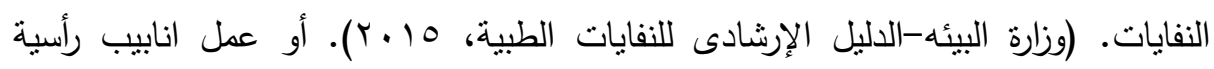

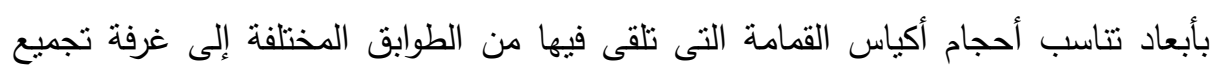
بالبدروم أو الدور الأرضي. أو بواسطة أنابيب شفط للمخلفات تسحبها اتوماتيكيا إلى مكان

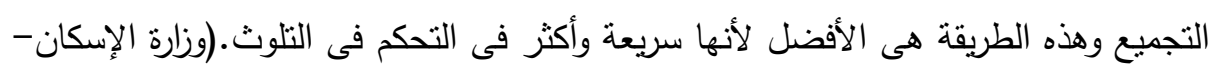

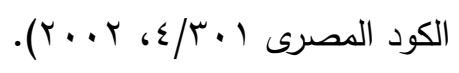

المرحلة الرابعة: التخزين المؤقت والتخزين المركزى لنفابات الرعابة الصحية ذات الخطورة:

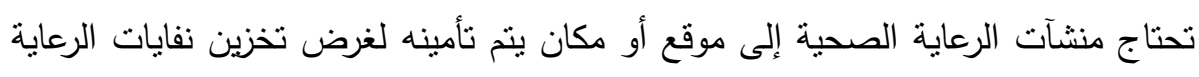
الصحية بعد تجميعها تمهيدا إما لنقلها لمحطة المعالجة أو إلى خارج المنشأة الصحية.

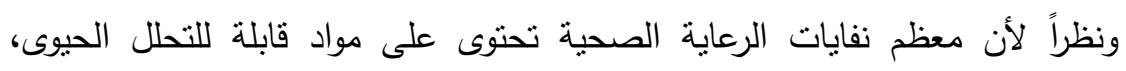

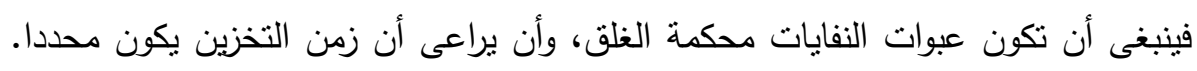

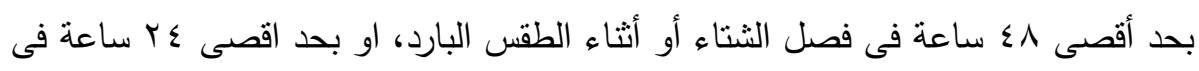

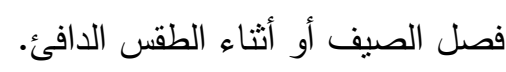

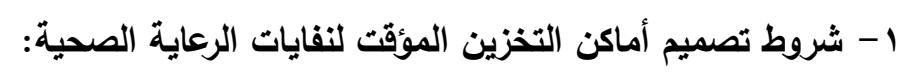
- أن تكون منطقة التخزين سهلة الاخول للعاملين فى نداول النفايات ولعربات (تروليات) نقل النفايات على حد سواء.

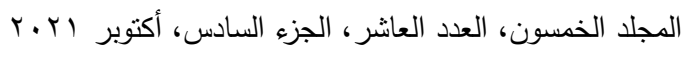

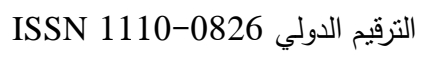

$$
\begin{aligned}
& \text { التزقيم الدولي الموحد الإلكتروني 3178-2636 }
\end{aligned}
$$


- - يجب تخزين تلك النفايات فى منطقة لا يتردد عليها العاملون أو المرضى أو الزائرون

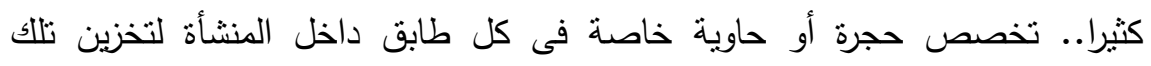

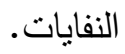

- - تركب لوحة على باب حجرة النخزين، وأن يكون الباب مزودا بآلية للغلق تمنع المرضى

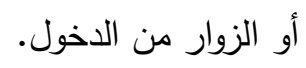

- أن تكون أرضية حجرة تخزين نفايات الرعاية الصحية صلبة وغير منفذة للسوائل. ويلزم

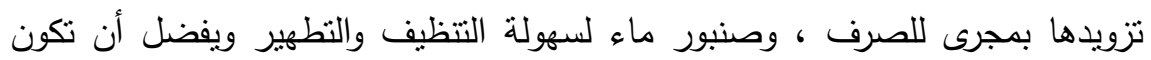
أرضية الحجرة من البلاط وجدرانها من السيراميك... أن تكون جيدة الإضاءة والتهوية.

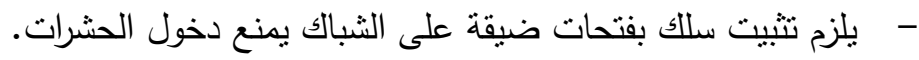
- - أن تكون متاحة للتخزين فى أى وقت. (وزارة البيئة، الدليل الأسترشادى للنفايات الطبية،

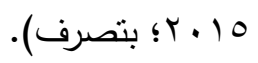
r- شروط تصميم مكان التخزين المركزى لنفايات الرعاية الصحية: نخزن النفايات الطبية

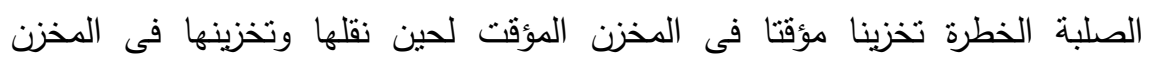

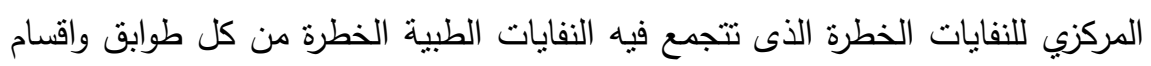

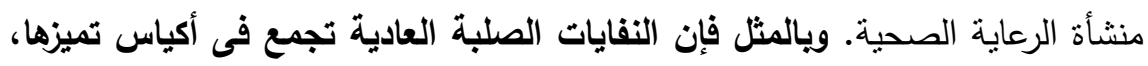
ثم تنقل فى حاويات وتخزن كنلك فى مخزن مركزى خاص بهان النها ويراعى في مكان النخزين المركزى ما يلي:

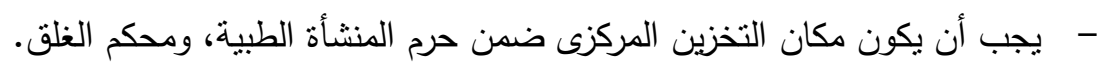

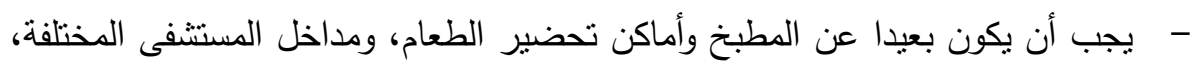
وأماكن إنظظار السيارات. - - يجب أن يكون مكان التخزين المركزي للنفايات الخطرة منفصلا عن مكان تخزين النفايات العادية، كما يجب أن يميز بوضوح عن طريق وضع إنشارات تحذير .

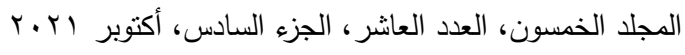

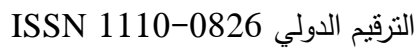

$$
\begin{aligned}
& \text { الترقيم الدولي الموحد الإلكتروني 3178-0826-2636 }
\end{aligned}
$$


- - ينبغى توفير حد أدنى لمساحة التخزين المركزى تمكنه من استيعاب النفايات الناتجة عن

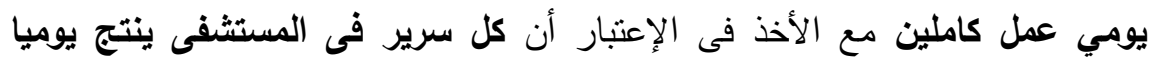
كيلوجرام من المخلقات.

- - يجب توفير وحدات تبريد خاصة للنفايات القابلة للتحلل فى حالة ضرورة تخزينها مدة ^ـ ساعة على الأقل قبل ترحيلها خارج المنشأة. - يجب تخصيص مكان منفصل بالنسبة للنفايات الكيمائية والصيدلانية ذات التأثير السمي على الخلايا (أدوية معالجة السرطانات)، وينبغى التعامل معها بشكل خاص ومن بلهن

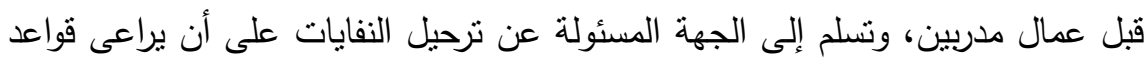
OSHA ، EPA

المرحلة الخامسة: نقل النفايات إلى خارج منشآت الرعاية الصحية: تتقل النفايات إلى خارج منشآت الرعاية الصحية فى الأحوال التالية:

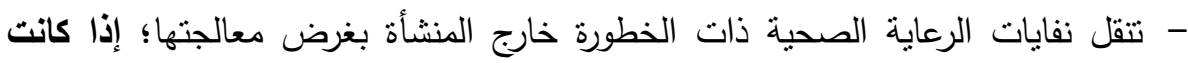
المنشأة المنتجة للنفايات ليس لديها مساحة مناسبة للمعالجة.

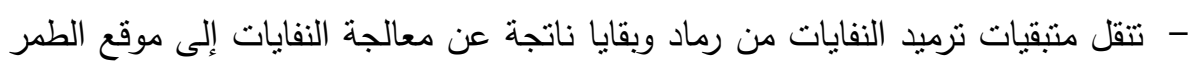

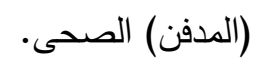
- تتقل النفايات الصلبة شبه المنزلية( البلدية ) إلى المحطات الوسيطة لتدويرها، أو لإعادة أستخدامها، أو نقلها لموقع الطمر (الدفن) الصحى.

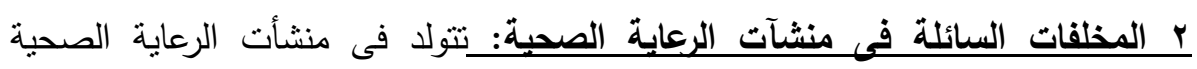
مخلفات سائلة عادية تتشأ من استخدام شبكة تغذية المنشأ بالمياة الجارية الصالحة للإستخدام ، وتستقبل المنصرف منها شبكة صرف صحى لهذه المياه بعد استخدامها ، وذلك بلك من خلال احواض غسيل الأيدى فى غرف المنشأة الطبية المختلفة، ودورات المياه، والمطابخ، والكافيهات، ....الخ ، وتتصل بشبكة مجارى الصرف الصنى فردى العمومية.

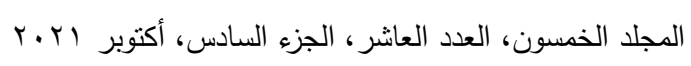

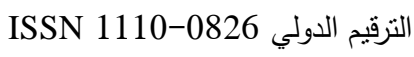
التزقيم الدولي الموحد الإلكتروني 3178-2636 
يمكن التخلص من الدم السائل، وبول وبراز المرضى، وسوائل الجسم والإفرازات فى

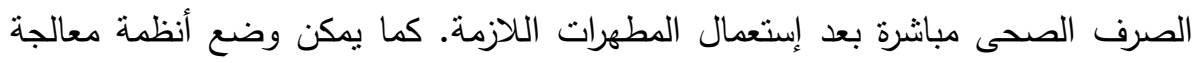

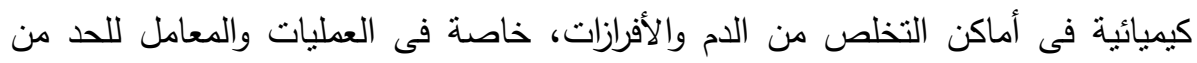

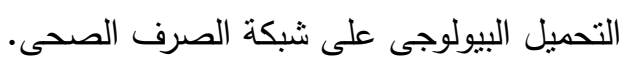

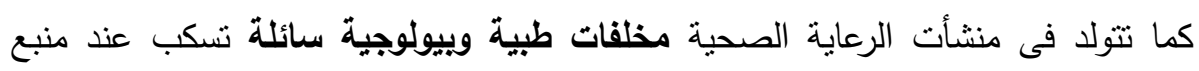

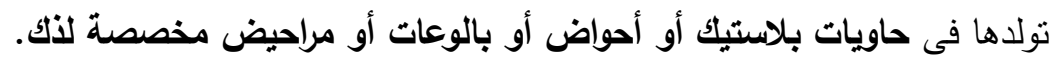

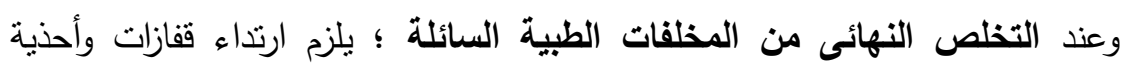
شديدة التحمل على أن تغسل بعد استخدامها فى كل مرة. يراعى الحرص على عدم تتاثر

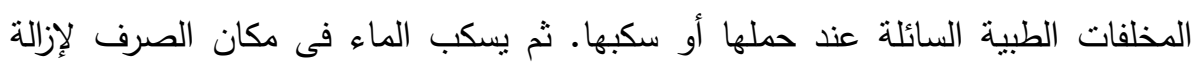

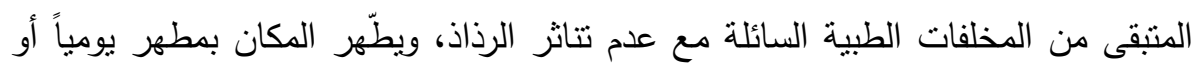
بشكل أكثر تكراراً عند الحاجة. كما يلزم تتظيف وتطهير الأوعية التى كانت تحوى المخلفات الطبية السائلة. تتغذى منشآت الرعاية الصحية عن طريق شبكة تغذية بالمياه..

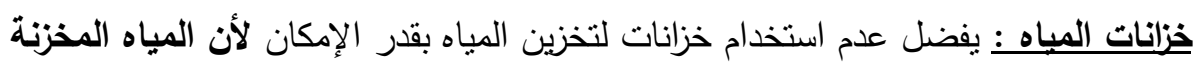
عرضة للتلوث البكتيري، ويراعى عند استخدام خزان أن يكون حجمه صغير قدر الإمكان، يستوعب التدفق المستمر من دون وجود أماكن فيه تؤدى لركود المياه، وبستخدم غطاء

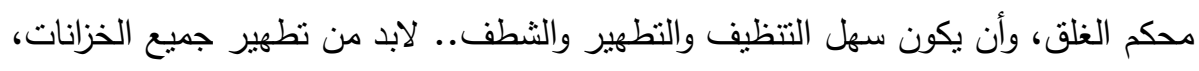

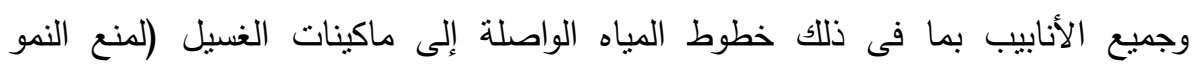

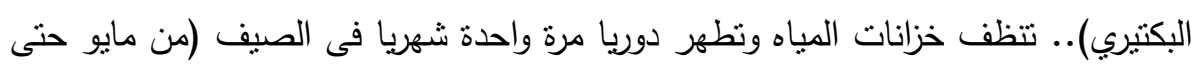
سبتمبر)، وكل ثلاثة أثشر فى الشتاء طبقا لقرار وزارة الصحة رقم وصلات المياه : يلزم مراعاة عدم وجودها غير مستخدمة أو تسمح بركود المياه.

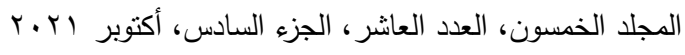

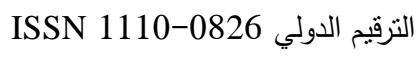

$$
\begin{aligned}
& \text { الترقيم الدولي الموحد الإلكتروني 3178-2636 }
\end{aligned}
$$


الصنابير: يلزم فتح الصنابير قليلة الإستخام مرة واحدة أسبوعياً لمدة ثُلاث دقائق على الأقل. أحواض غسل الأبدى: تخصص لهذا لغئل الغرض فقط. المخلفات السائلة في وحدات الغسيل الكلوي: يجب أن نطابق مواصفات المياه المستخدمة

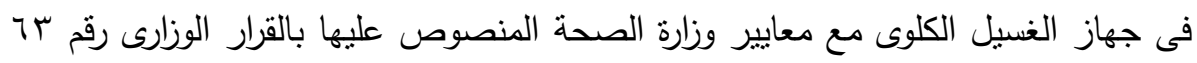

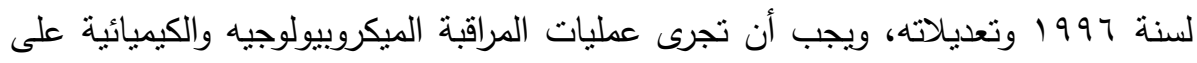

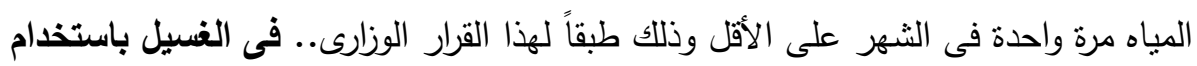

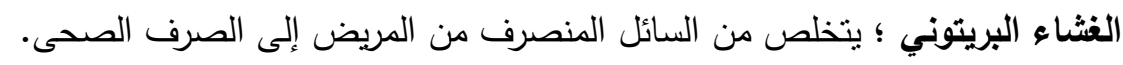

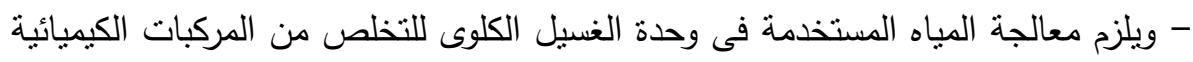

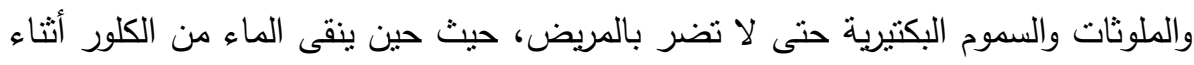

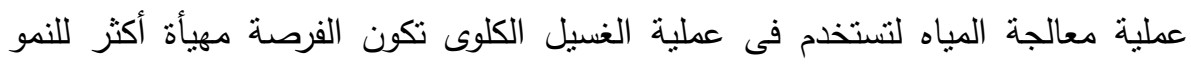
البكتيرى، لذا ينحتم توخى الحرص والعناية فى كل مرطلة أثثاء عملية معالجة العياه للنقليل

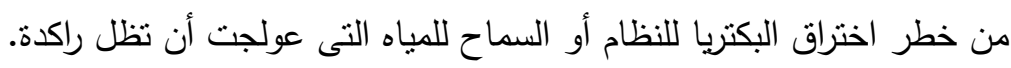

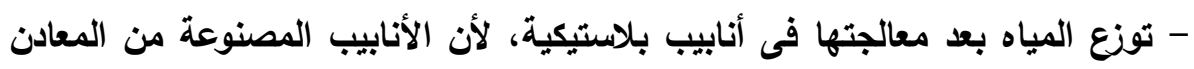

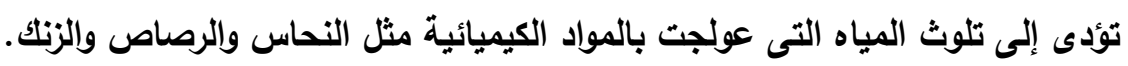
- يراعى استخدام أقل عدد ممكن من الوصلات المناه المنية (الزوايا).

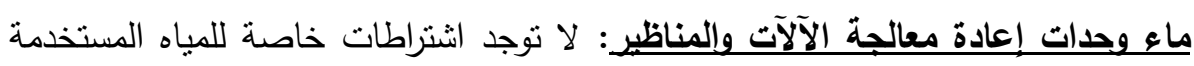

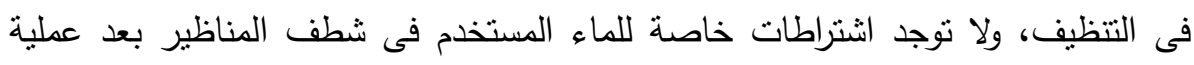

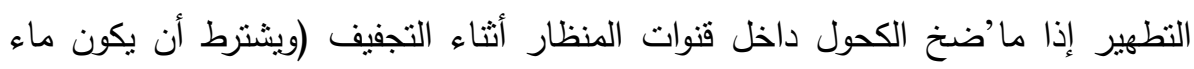

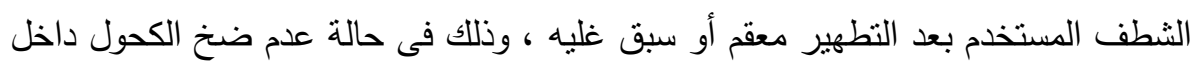
(القنوات). ماء أحواض العلاج الطيعي: يجب أن تزود أحواض العلاج الطبيعي بنظام لتنقية المياه

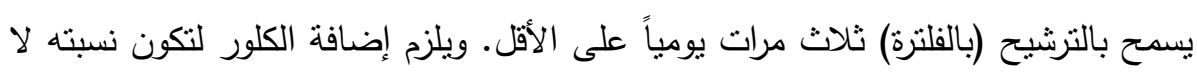

$$
\begin{aligned}
& \text { المجلد الخمسون، العدد العاشر ، الجزء السادس، أكتوبر بr.r. }
\end{aligned}
$$

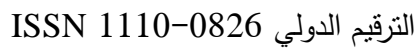

$$
\begin{aligned}
& \text { التزقيم الدولي الموحد الإلكتروني 3178-2636 }
\end{aligned}
$$




\section{مجلة العلوم البيئية \\ كلية الدراسات العليا والبحوث البيئية - جامعة عين شمس البئ \\ مجد متبولي عطية غريب وآخرون}

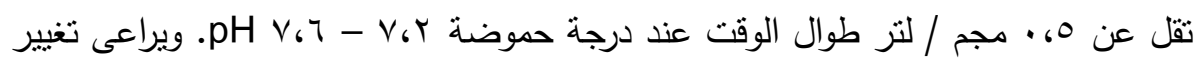

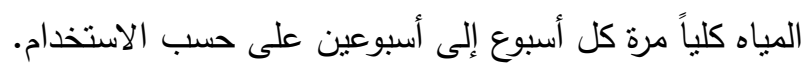

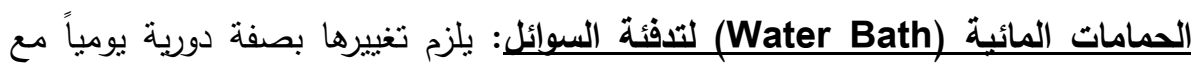
إضافة مطهر مناسب واتباع تعليمات الشركة المصنعة، ويجب تلافى ترسب الأملاح والتكلسات.

مياه العنابة الطية: يستخدم الماء العادى فى العناية بالأطفال حديثى الولادة، ويستخدم الماء المعقم فى حالات تفشى العدوى بالوحدة، حدوث تلوث فى مصدر المياه، وزن الأطفال المبنسرين أقل من . .0 اجم، مع الأطفال منقوصى المناعة، حالة استخدام أجهزة اختراقية.. ويستخدم الماء المعقم فى العناية بالجروح، عند شطف الجروح والجن القطوع الجراحية.

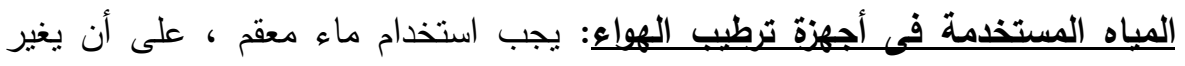
بصفة يومية. الماء المستخدم فى تنظف البيئة وأسطح العمل: يكون ماء جارى نظيف. ولا اشتراطات خاصة. r- المخلفات الغازية فى منشآت الرعاية الصحية: تحدث حالات من العدوى داخل المنشآت الصحية نتيجة التعرض للميكروبات التى تنتشر بالهواء من مصادر بيئية أخرى المئه

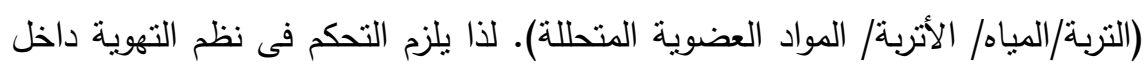

المنشآت الصحية للحد من انتشار تلك الميكروبات داخل بيئة المنشأت الصحية. ومن أمثلة تلك الميكروبات؛ الفيروسات المنقولة عن طريق الهواء والرذاذ منها الفيروسات التقليدية كالحصبة والجديرى المائى وغيرها. وفيروسات حديثة كفيروسات

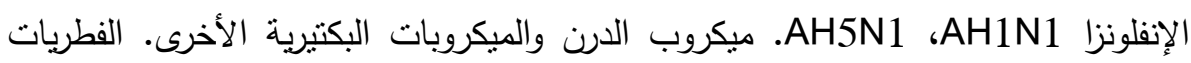

Aspergillums spp. منل

\section{نظم التحكم في الههواء (تكيف وتهوية الهواء) داخل المنشآت الصحية:}

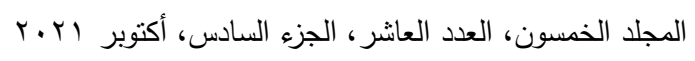

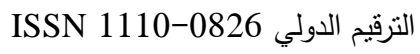

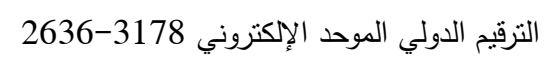


تكيف الههواع يهدف إلى توفير بيئة ذات درجة حرارة ورطوبة مريحة وملائمة. ويقيم التكييف

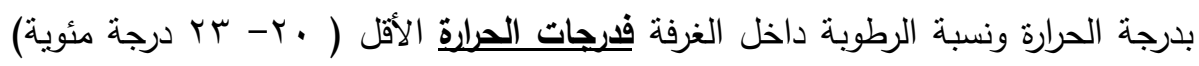
تكون عادة مرتبطة بغرف العمليات، غرف الإجراءات النظيفة، والمناظير • ودرجات الحرارة

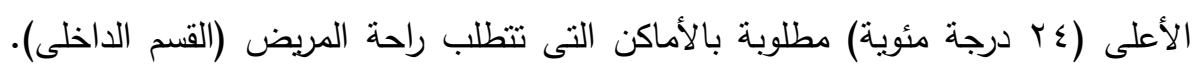

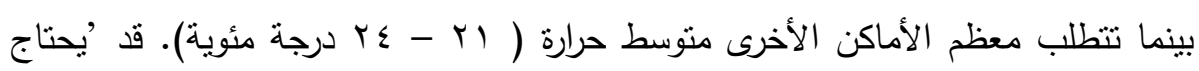
إلى درجات حرارة خارج هذا المدى فى مناطق محدودة بصورة تعتمد على متطلبات العاملين

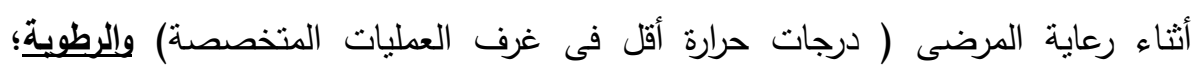

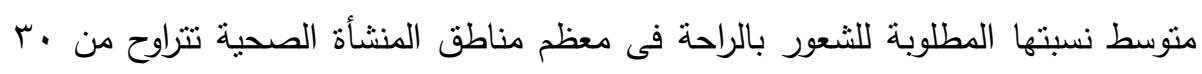

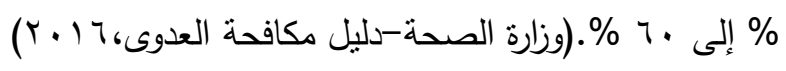
وتهوية الهواء تعنى إدخال الهواء الخارجى وتوزيعه داخل المبنى أو إعادة دوران الهواء

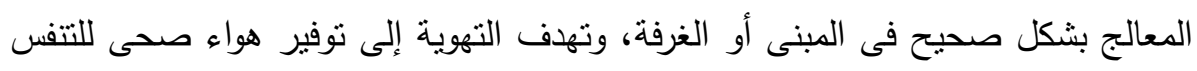

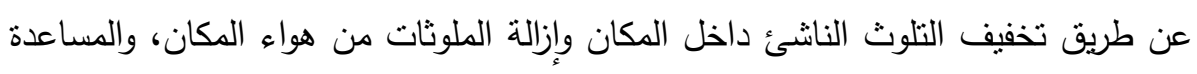

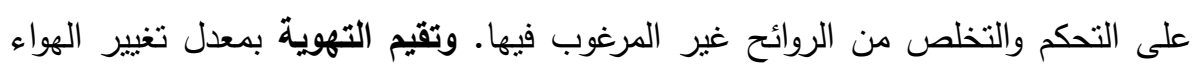

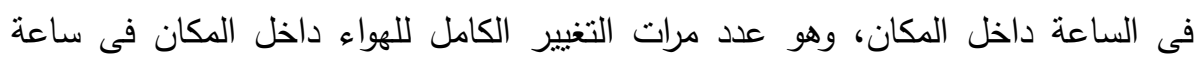

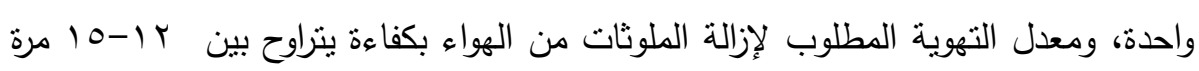
في الساعة. والعناصر الأساسية للتهوية: فئة معدل التهوية؛ معدل ضخ الهواء من خارج المبنى إلى الداخل ويعبر عن معدل التهوية بواسطة معدل تغيير الهواء/الساعة. اتجاه تدفق الهواء؛؛ يجب أن يكون مسار الهواء من المناطق النظيفة إلى المناطق الملوثة.

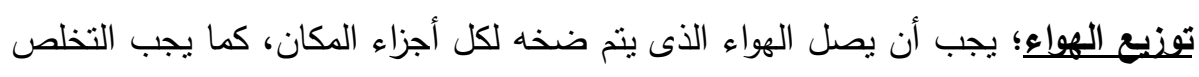
من ملوثات الهواء الناشئة بالمكان بطريقة تتسم بالكفاءة.

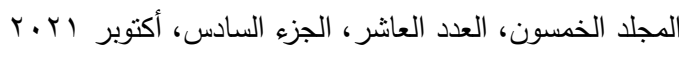

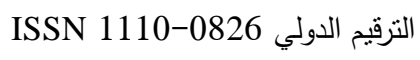

$$
\begin{aligned}
& \text { الترقيم الدولي الموحد الإلكتروني 3178-2636 }
\end{aligned}
$$




$$
\text { مجلة العلوم البيئية }
$$

كلية الدراسات العليا والبحوث البيئية - جامعة عين شمس لئي

مجد منبولي عطية غريب وآخرون

ضغط الهواء؛ يرجع الضغط الموجب أو السالب للهواء إلى اختلاف الضغوط بين المناطق

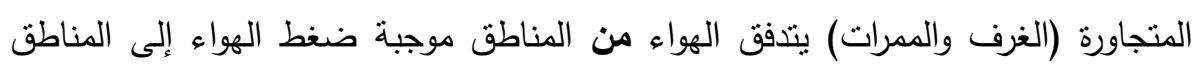

سالبة ضغط الهواء. 


\section{ترشيح الهواء (فلترته): أنواع الفلاتر :}

1- الفلاتر منخفضة - متوسطة الكفاءة (90\% Efficiency)

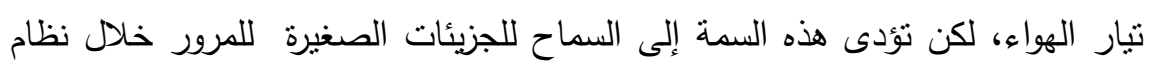

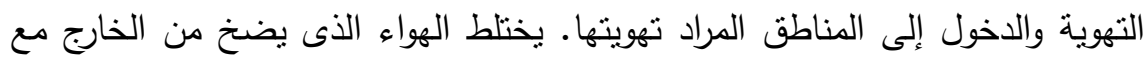

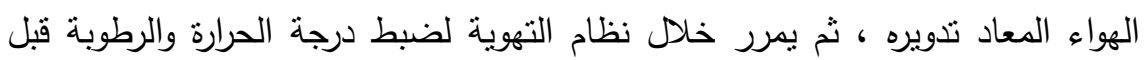
المرور على النوع الثاني من الفلاتر.

r-الفلاتر عالية الكفاءة (HEPA Filter).: تبلغ كفاءة الفلاتر عالية الكفاءة (على

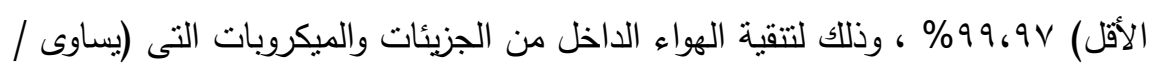

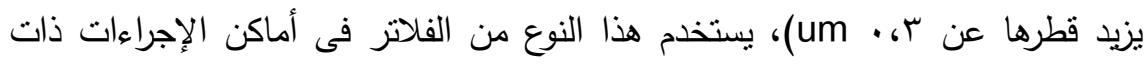
الطبيعة الخاصة (زرع النخاع، عمليات العظام، العزل الوقائى، ..).

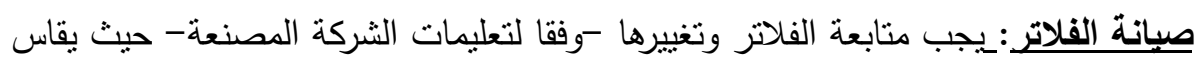
اختلاف ضغط الهواء قبل وبعد الفلتر عن طريق المانومتر ، وفرق الضغط الذى يتعدى الحد

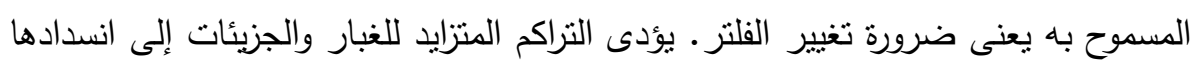

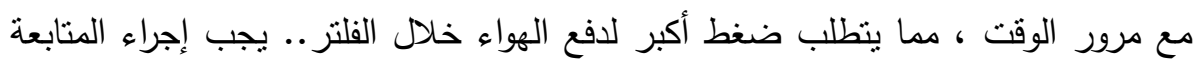

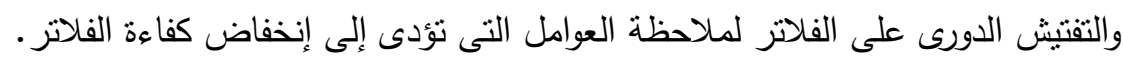

أنواع أنظمة التهوية. 1-التهوية الطبيعية.

r-التهوية الميكانيكية.

ب-التهوية المتلازمة: تعتمد على التهوية الطبيعية، ويستعان بوسائل التهوية الميكانيكية للمساعدة. وذلك حالة تعذر إمكانية الاعنماد على التهوية الطبيعية أو الميكانيكية كلاً على حده.

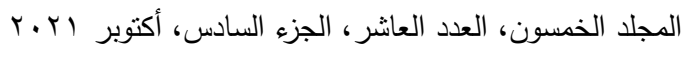

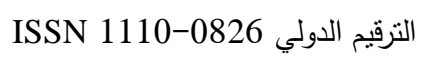

$$
\begin{aligned}
& \text { الترقيم الدولي الموحد الإلكتروني 3178-2636 }
\end{aligned}
$$


التهوية الطبيعية داخل المنشآت الصحية:_توجه القوى الطبيعية - الرياح، قوة الطفو

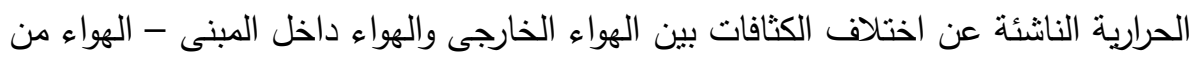

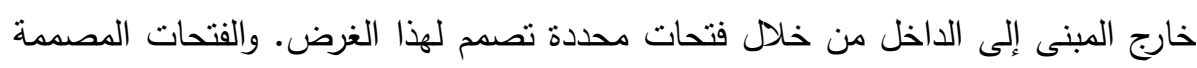

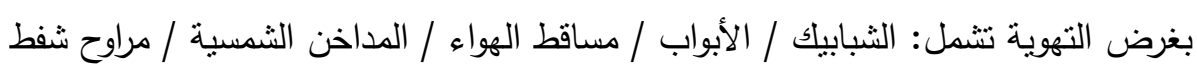
ميكانيكية محدودة القدرة. ويعتدد نظام التهوية الطبيعية لأى مبنى على: المناخ / تصميم المبنى / السلوك البشرى. التهوية الميكانيكية داخل المنشآت الصحية:_تعتمد التهوية الميكانيكية على استخدام مراوح ميكانيكية لتوجيه الهواء، حيث تركب مراوح نوجيه الهواء مباشرة فى النوافذ أو الجدران

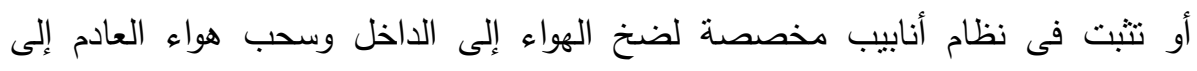
الخارج. (Heating, Ventilation, Air Conditioning ويحتوى نظام التهوية الميكانيكية System - HVAC)

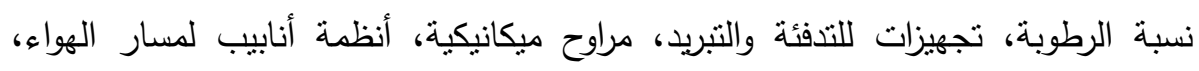
مخرج للهواء، وسائل تسجيل مؤشرات ومراقبة للنظام، وسائل لتوزيع الهواء.

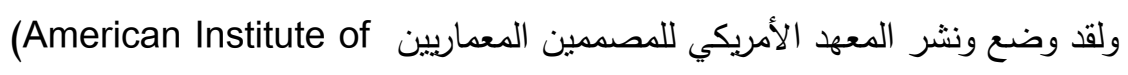
Architects (AIA)) الجديدة وقواعد تطوير المنشأت الموجودة. تراعى هذه المعايير خواص وجودة الهواء (معدل

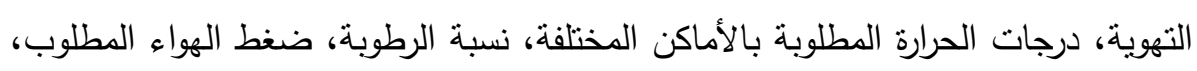
معدل تغيير الهواء فى الساعة) لكل منطقة من مناطق الرعاية الصحية. 
ا-يدخل الهواء الخارجى إلى نظام التهوية بحيث بمر على مرشحات (فلانتر) منخفضة

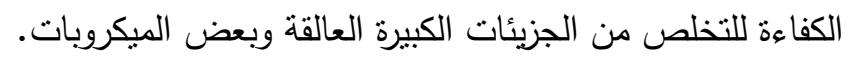
ז-بمرر الهواء خلال شبكة توزيع الهواء حيث ينكيف الهواء لضبط درجة الحرارة ونسبة العبات

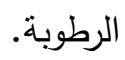
ب-يمرر الهواء خلال فلاتر إضافية عالية الكفاءة لتتقية الهواء ثم بوزع إلى مناطق المبنى

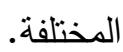

ع-يثفط الهواء خلال أنابيب راجعة حتى يصل إلى وحدة التهوية المركزية.

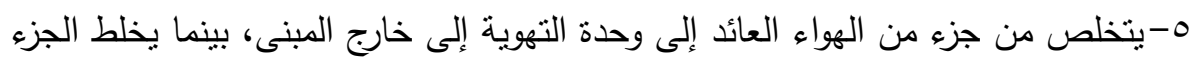

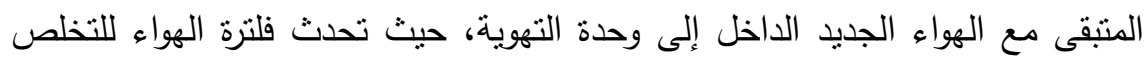

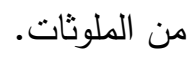
צ- الهواء القادم من دورات المياه أو المناطق الملوثة بسحب إلى الخارج مباشرة فى أنابيب منفصلة. - V الهواء القادم من غرفة رعاية مرضى أمراض الجهاز التتفسي المعدية بسحب إلى إلى

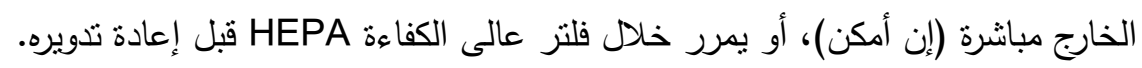

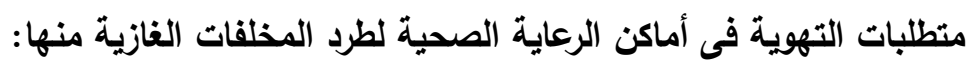
يبين الجدول (ץ) منطلبات التهوية فى أماكن الرعاية الصحية لطرد المخلفات الغازية منها.

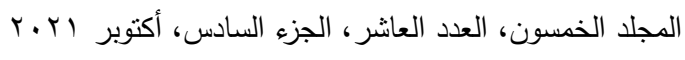

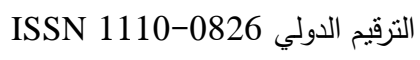

$$
\begin{aligned}
& \text { الترقيم الدولي الموحد الإلكتروني 3178-0826-2636 }
\end{aligned}
$$


مجلة العلوم البيئية

كلية الدراسات العليا والبحوث البيئية - جامعة عين شمس البئ

مجد متبولي عطية غريب وآخرون

\begin{tabular}{|c|c|c|c|c|c|c|c|}
\hline \multicolumn{8}{|c|}{ جدول (ب): متطلبات التهوية في أماكن الرعاية الصحية. } \\
\hline المناسبة & الرطوية & باستخاء الدويرة & الخهاء & التغير الهل & ألتغير عداد مرات الهواء & اتجاه حركة & 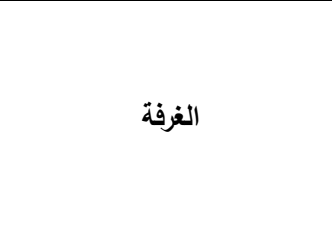 \\
\hline \multicolumn{8}{|c|}{ غزف الرعاية الصحية } \\
\hline$T \leq-Y 1$ & - & - & - & 7 & r & - & غرف المرضى \\
\hline- & - & - & نعر & 1. & r & 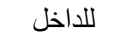 & الحمامات \\
\hline$r \leq$ & - & $\gamma$ & - & IT & r & 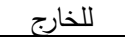 & غرف العزل الوقائى \\
\hline$r \leqslant-Y)$ & - & ע & نعم & ir & r & 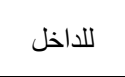 & 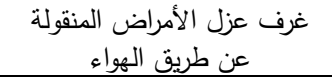 \\
\hline- & - & ע & نعم & 1. & - & للاللالنسبة & غرف تحضير المريض \\
\hline- & - & - & - & r & - & - & الممرات بين غرف المرضي \\
\hline$r \leqslant-Y)$ & - & - & - & 1 & r & - & فرافة الولادة الطبيعية/ \\
\hline \multicolumn{8}{|c|}{ غرف العمليات والإجراءات الجراحية والطوارئ } \\
\hline$r M-T$. & T. T. & $\gamma$ & - & 10 & r & للخارج & غرفة العمليات/المناظير الجراحية \\
\hline$r T-r$. & ז. r. & $\gamma$ & - & 10 & r & 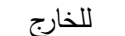 & غرفة عمليات الولادة \\
\hline r) & ч. & $\gamma$ & - & 7 & r & - & غرفة الإفاقة \\
\hline$r \leqslant-Y 1$ & ᄀ. - r. & $\gamma$ & - & 7 & r & - & العناية المركزة \\
\hline$r \leqslant-r \mid$ & - & - & - & 7 & r & - & العناية المنتسطة \\
\hline TY-TY & T. T. & $y$ & - & 7 & r & - & غرفة العناية بحديثى الولادة \\
\hline \multicolumn{8}{|c|}{ غرف الاستقبال والطوارئ } \\
\hline$r \leqslant-r)$ & ז. & ע & - & 10 & r & 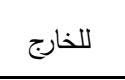 & استقبال الحوادثة عليات الحوادث (بما فيهات الصغيات \\
\hline$r M-r$. & T. - r. & $\gamma$ & نعم & IT & $r$ & للاخل & غرف مناظير الجهاز التنفسى \\
\hline$r\{-r \mid$ & - & - & نعم & ir & r & 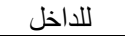 & غرفة تصنيف المرضي \\
\hline$T \leq-Y 1$ & - & - & نعح & IT & r & ل للاخل & أماكن إنتظار الطوارئ \\
\hline$r \leq-T_{1}$ & ז. r. & $\gamma$ & - & 10 & $r$ & ل ل ل ل لخارج & غرفة العمليات الصغرى / الغرز \\
\hline- & - & - & - & $\varepsilon$ & - & 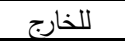 & غرفة الأدوية \\
\hline- & - & - & - & $\varepsilon$ & - & 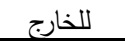 & 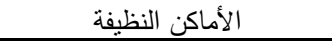 \\
\hline
\end{tabular}

622

المجلد الخمسون، العدد العاشر ، الجزء السادس، أكتوبر الr.r.

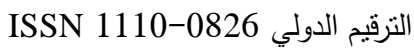

التزقيم الدولي الموحد الإكتروني 3178-2636 


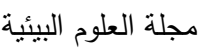

كلية الدراسات العليا والبحوث البيئية - جامعة عين شمس البية

مجد متبولي عطية غريب وآخرون

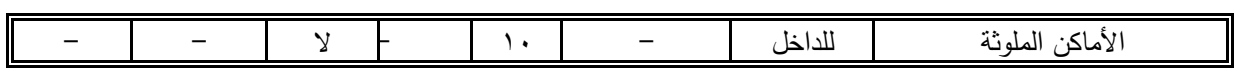

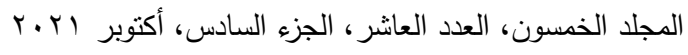

التزقيم الدولي

الترقيم الدولي الموحد الإلكتروني 3178-2636 
مجلة العلوم البيئية

كلية الدراسات العليا والبحوث البيئية - جامعة عين شمس الئي

مجد متبولي عطية غريب وآخرون

\begin{tabular}{|c|c|c|c|c|c|c|c|}
\hline المرارة & $\begin{array}{l}\text { الرطوية } \\
\text { \% }\end{array}$ & باستخداءم الداءير & الخهاء & التفليرل الهول & أتل أتيير الهواء مرات & الجهاه & الغرفة الغ \\
\hline \multicolumn{8}{|c|}{ أماكن الفحص والعلاج: } \\
\hline- & - & - & - & 7 & - & - & الخارجية (عدا عيادات العصى الديادة) \\
\hline- & - & - & - & 7 & - & - & غرفة العلاج \\
\hline- & - & - & - & 7 & - & ل للاخل & غرفة العلاج الطبيعى/المائي \\
\hline- & $\begin{array}{c}-r . \\
1 .\end{array}$ & - & - & 1 & r & - & مناظيرالجهاز الهضمى \\
\hline- & - & $\gamma$ & نعم & 1. & - & 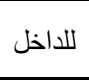 & غرفة إعادة معالجة مناظير \\
\hline \multicolumn{8}{|c|}{ أقسام الأشعة } \\
\hline- & - & - & - & 7 & - & - & غرفة الأشعة التشخيصية \\
\hline- & - & - & نعم & Ir & $r$ & ل للاخل & أماكن انظظار الأشعة \\
\hline- & - & $y$ & نعم & 7 & - & لللاخل & معمل الميكروبيولوجي \\
\hline- & - & ע & نعم & ir & - & ل للاخل & غرفة العينات بعدالوفاة \\
\hline- & - & - & نعم & 1. & - & لللاخل & غرفة حفظ الموتى \\
\hline \multicolumn{8}{|c|}{ التعقيم } \\
\hline- & $\begin{array}{c}-r . \\
t .\end{array}$ & y & نعم & 1. & - & 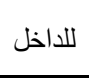 & غرفة التعقيم بأوكسيد الإيثيلين \\
\hline- & - & - & نعم & 1. & - & 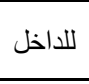 & غرفة أجهزة التعقيم \\
\hline \multicolumn{8}{|c|}{ أماكن الغدمات : } \\
\hline- & - & - & - & $\varepsilon$ & - & للخارج & الصيدلية \\
\hline- & - & ע & - & 1. & - & - & مركز إعداد الطعام (مطبخ \\
\hline- & - & - & نعم & 1. & - & - & المغسلة (بشكل عام) \\
\hline- & - & ע & نعم & 1. & - & 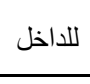 & غرفة المفروشات الملوثة(منطقة \\
\hline- & - & - & - & $r$ & - & 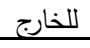 & غرفة تخزين المفروشات النظيفة \\
\hline- & - & - & نعم & 1. & - & 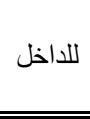 & 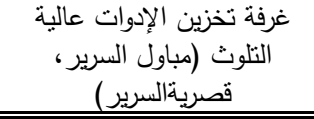 \\
\hline
\end{tabular}

624

المجلد الخمسون، العدد العاشر ، الجزء السادس، أكتوبر اYr.r

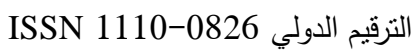

التزقيم الدولي الموحد الإلكتروني 3178-0826-2636 


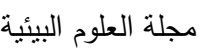

كلية الدراسات العليا والبحوث البيئية - جامعة عين شمس آلئة

مجد منبولي عطية غريب وآخرون

\begin{tabular}{|c|c|c|c|c|c|c|c|}
\hline- & - & $y$ & نعم & 1. & - & ل للاخل & غرفة أدوات النتظيف \\
\hline
\end{tabular}

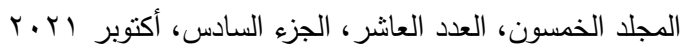

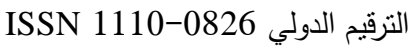

الترقيم الدولي الموحد الإلكتروني 3178-2636 
تابع: جدول (广):

\begin{tabular}{|c|c|c|c|c|c|c|c|}
\hline الدرارة & الرطوية & لواستخاء & الخالياء & التغليرل & 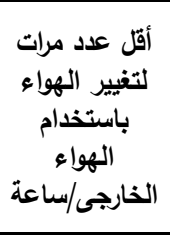 & الهركة & الغرفة \\
\hline \multicolumn{8}{|c|}{ أماكن تخزين المستلزمات } \\
\hline - & - & y & نعم & 1 & - & للاخل & غرفة تخزين الألدوات الملوثة \\
\hline- & r. - r. & $\gamma$ & - & $\varepsilon$ & - & ل ل لخارج & غرفة فحص الأدوات النظيفة \\
\hline - & $\begin{array}{c}\text { بحد اقصى } \\
\text { V. }\end{array}$ & - & - & $\varepsilon$ & - & للخارج & غرفة تخزين الأدوات المعقمة \\
\hline
\end{tabular}

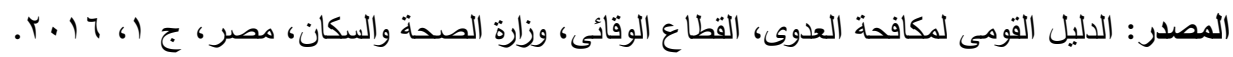

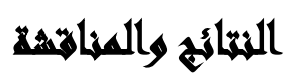

مع تقدم الوعى نحو التعامل الآمن للمخلفات حفاظا على البيئة بصفة أساسيا، وللمساهمة فى منع إنتشار العدوى فى منشآت الرعاية الصحية، وبعد سرد حجم التعم مهام

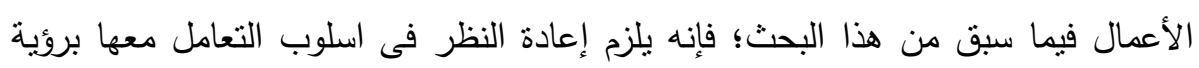

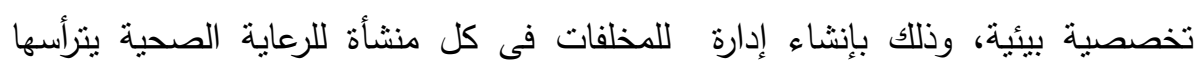

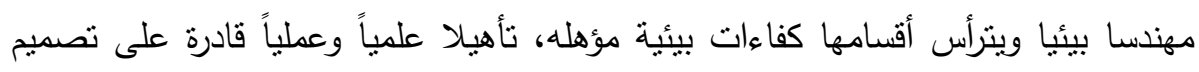

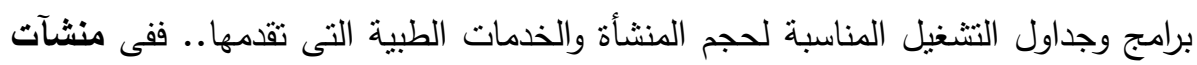
الرعاية الصحية كبيرة الحجم؛ فإن إدارة المخلفات بها يمكن أن تتسع أقسامها ووحداتها

$$
\begin{aligned}
& \text { لتنمل التالى: } \\
& \text { ( ) قسم المخلفات الصلبة. } \\
& \text { r) قسم المخلفات السائلة. }
\end{aligned}
$$

626

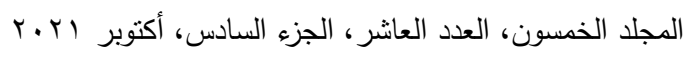

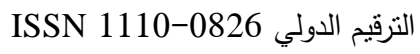

$$
\begin{aligned}
& \text { الترقيم الدولي الموحد الإلكتروني 3178-0826-2636 }
\end{aligned}
$$


كلية الدراسات العليا والبحوث البيئية - جامعة عين شمس البية

مجد منبولي عطية غريب وآخرون

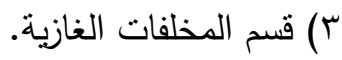

$$
\begin{aligned}
& \text { ع) قام المخلفات الباثولوجية. } \\
& \text { 0) قدم المخلفات البكترولوجية. }
\end{aligned}
$$

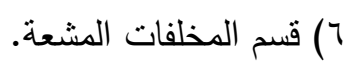

$$
\begin{aligned}
& \text { ( ) قدم المخلفات الكيمائية والأدوية. } \\
& \text { ^) وحدة معالجة المخلفات. } \\
& \text { 9) وحدة التكهين. } \\
& \text { • ( ) (1) وحدة النظافة. }
\end{aligned}
$$

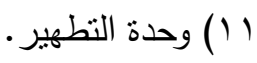

$$
\begin{aligned}
& \text { r ا ) وحدة التعقيم. } \\
& \text { r 1 ) وحدة المحرقة للنفايات الطبية الخطرة. } \\
& \text { ع ( ) وحدة المحطة الوسيطة للمخلفات الصلبة العادية. } \\
& \text { 1) وحدة المدفن الصحى. }
\end{aligned}
$$




$$
\text { مجلة العلوم البيئية }
$$

كلية الدراسات العليا والبحوث البيئية - جامعة عين شمس البية

مجد متبولي عطية غريب وآخرون

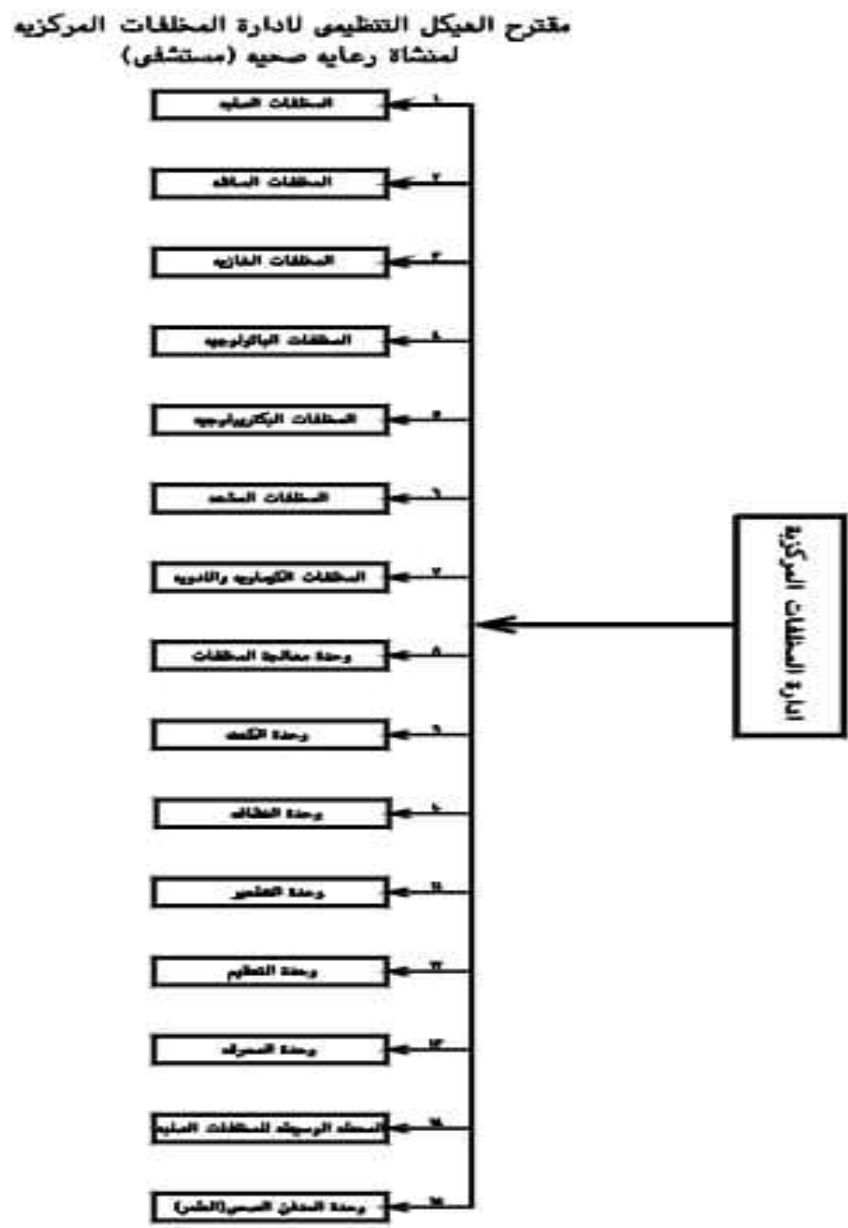

شكل (1): الهيكل التتظيمى لمقترح إنشاء إدارة للمخلفات فى منشأة رعاية صحية.

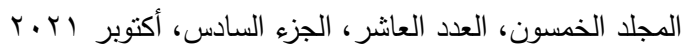

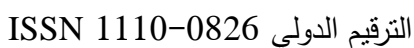

$$
\begin{aligned}
& \text { الترقيم الدولي الموحد الإلكتروني 3178-2636 }
\end{aligned}
$$


وتختص هذه الأقسام والوحدات بمالمهام التالية:

ا - قسم المخلفات الصلبة: يختص بالتعامل مع المخلفات الصلبة التى تشكل نحو \%1\% من مخلفات المنشآت الصحية، وتتشل: مخلفات المكاتب، وغرف سكن الأطباء

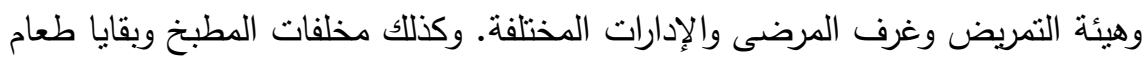
المرضى وهى نفايات عضوية مرنبطة بالطعام. ونفايات الورق والصناديق ومواد التغليف وهن واليف

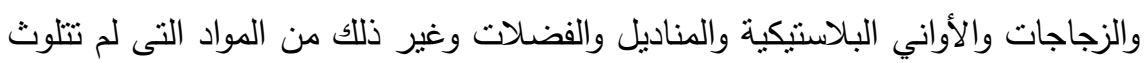
بسوائل الجسم.

r - قسم المخلفات السائلة: يختص بالتعامل مع المياه المستخدمة فى شبكة تغذية

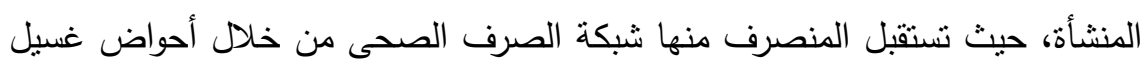

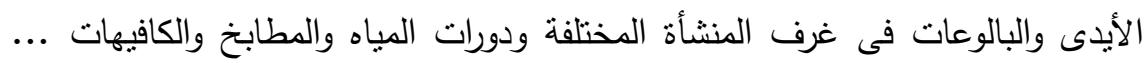
إلخ، والتى تتصل بشبكة مجارى الصرف الصحى العمومية. وبالتخلص من الدم السائل وبول وبراز المرضى وسوائل الجسم والإفرازات فى شبكة لهئه

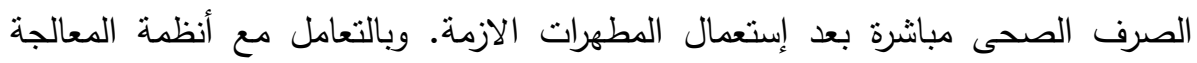

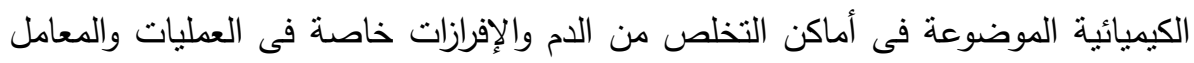
للحد من الحمل البيولوجى على شبكة الصرف الصحى. وبالتعامل مع المخلفات الطبية

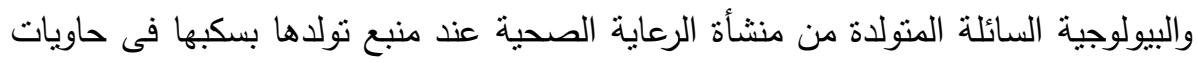
بلاستيك أو أحواض أو بالوعات أو مراحيض مخصصة لذلك. وبالتعامل مع خزانات المياه،

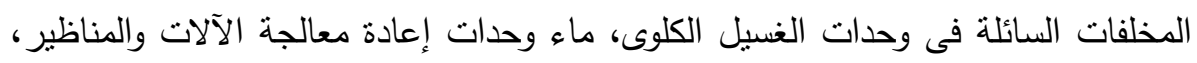

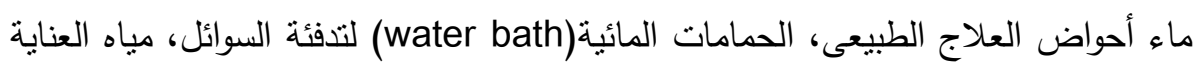
الطبية،مياه أجهزة ترطيب الهوا، مياه نتظيف البيئة وأسطح العمل.

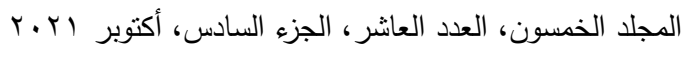

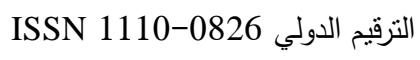

$$
\begin{aligned}
& \text { الترقيم الدولي الموحد الإلكتروني 3178-0826-2636 }
\end{aligned}
$$


ץ- قسم المخلفات الغازية: يختص بالنحكم فى نظم التهوية والتكيف داخل منشأة

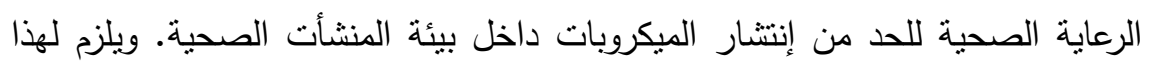

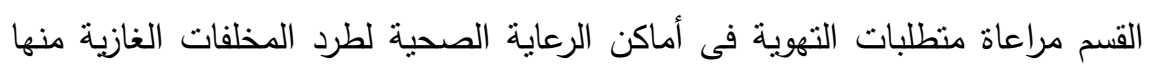

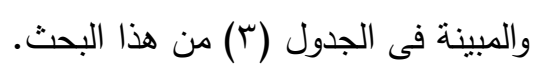
ع - قسم المخلفات الباتولوجية: يختص بالتعامل مع كافة أنواع النفايات التى تنتج النتج

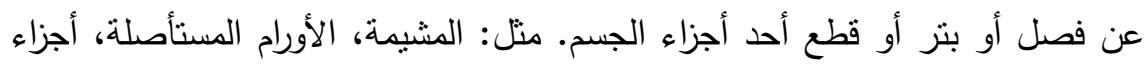

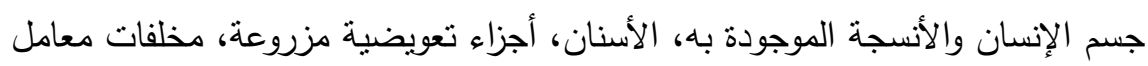

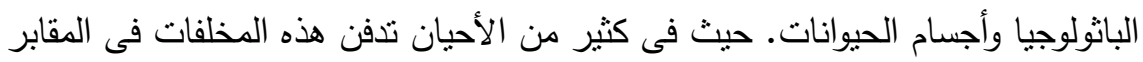

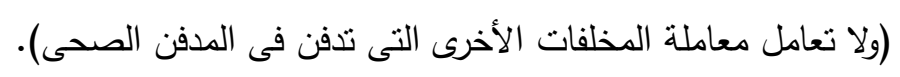

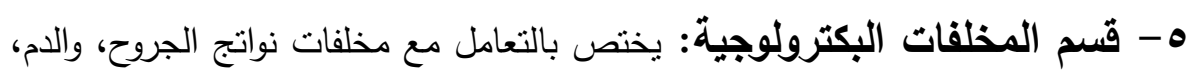
والبول والبراز، وغيرها. وأطباق بترى المستخدمة لزراعة وقياس الكائنات الدقيقة

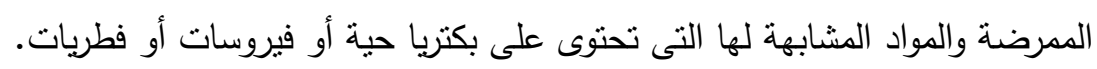

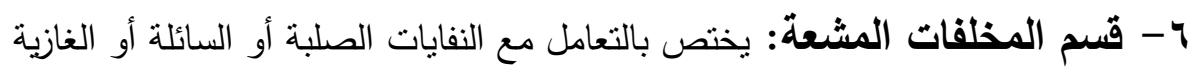

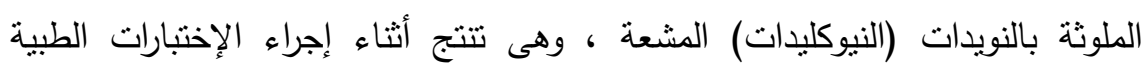

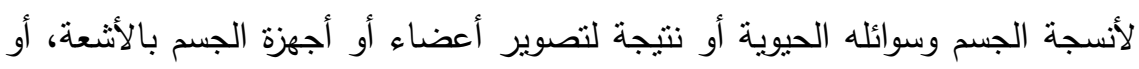

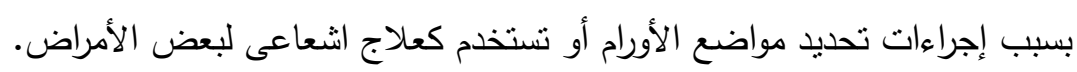

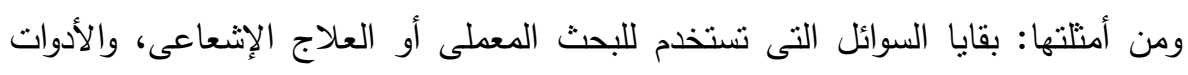

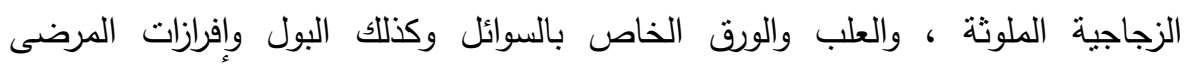
الدعالجين بمواد إثعاعية، أو الذين أجريت لهم اختبارات تثخيصية باستخدام هذه المواد. 
بالنسبة للمصادر المغلقة ذات فترة نصف العمر الحيوي الطويل؛ فيتم التتسيق لتداولها والتخلص منها مع هيئة الطاقة الذرية حسب صنف النفاية المشعة.. وبالنسبة للمصادر المفتوحة ذات فترة نصف العمر الحيوي القصير ؛ فيتم التتسيق لتداولها والتخلص منها مع هينه إدارة الوقاية من الإشعاع بوزارة الصحة حسب دنف صنف النفاية المشعة.

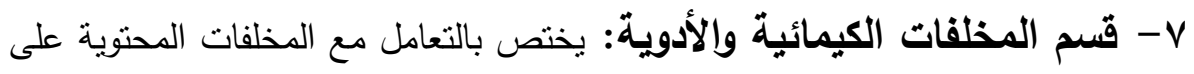

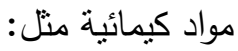
مخلقات المعمل: مثل المواد المستخدمة داخل المعل والزجاجات الفارغة للمواد الكيميائية الدوائية أو المستخدمة فى المعمل، والمطهرات التى انقضت فترة صلاحيتها أو لم تعد هناك حاجة إليها، والمواد المستخدمة فى التشخيص والمواد السامة والمسببة للتآكل والمنظفات ...

المخلفات الكيميائية المسبية للتغيرات الجنينية : وتتثمل المخلفات عالية الخطورة والتى تسبب طفرة وراثية أو نتوه وراثى أو سرطان ، وتحنوى عادة على مواد ذات خواص سامة للجينات. ومن أمثلنها: العقاقير المستخدمة لعلاج السرطان وبعض المواد الكيمائية.

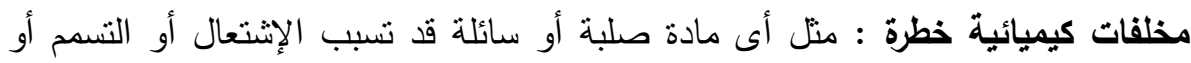
التأكل أو الحساسية أو الإلتهاب أو التفاعل أو كونها مسرطنة أو مشوهة أو مسببة للفقرات الوراثية.. وكذلك المطهرات التى انقضت فترة صلاحيتها أو لم تعد هناك حاجة إليها،

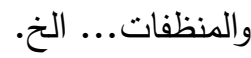
المواد الكيميائية المثبطة للخلايا: والتى تدخل ضمن تركيب العلاج الكيميائي للأورام. نفايات معلية ( مختبرية): وهى متبقيات الكواثف التى تستخدم فى مختلف أنواع التحاليل

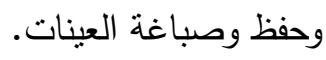

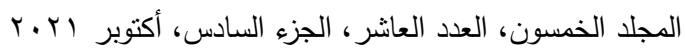

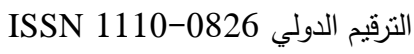

$$
\begin{aligned}
& \text { الترقيم الدولي الموحد الإلكتروني 3178-2636 }
\end{aligned}
$$


النفايات الصيدلانية: وهى المخلفات التى تحتوى على مواد ومستحضرات دوائية التى انتهى

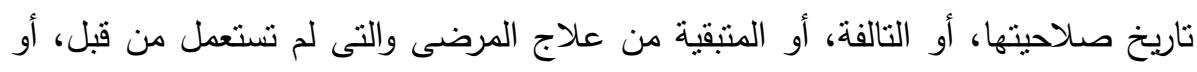

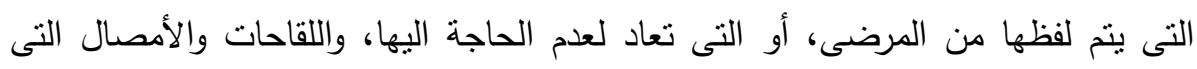
انقضت فترة صلاحيتها.

^- وحدة معالجة المخلقات: تختص هذه الوحدة بإزالة العناصر الخطرة من المخلفات. ويتحدد منها إما التخلص النهائي من المخلف (كالطمر فى المدفن الصحى) أو التدوير بالتحويل إلى مصدر لإنتاج الطاقة.

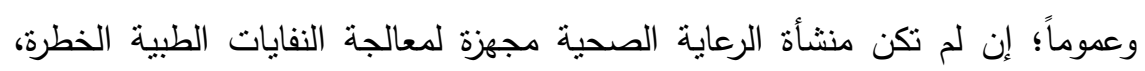
عندئذ تنقل النفايات الخطرة المجمعة من المخزن المركزى إلى مكان معالجتها خارج

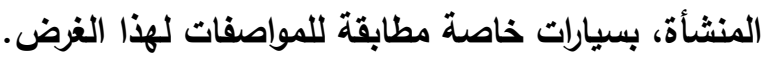
9- وحدة التكهين: وفيها نتشكل لجنة من أعضاء بالمنشأة للبت فى شأن مدى

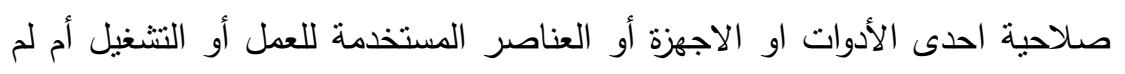
يعد هناك حاجة إليها و تحويلها إلى مخلف بلزم التخلص منه وإسقاطه من العهدة. • - - وحدة النظافة: تختص هذه الوحدة بعملية إزالة المواد العضوية والأتربة والقاذورات مما يؤدى إلى التخلص من نسبة كبيرة من الميكروبات.. حيث تستخدم

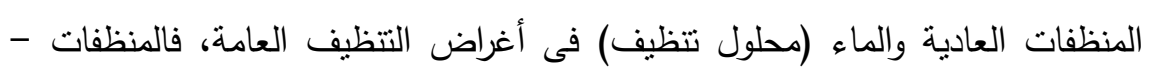

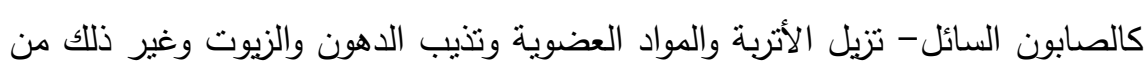

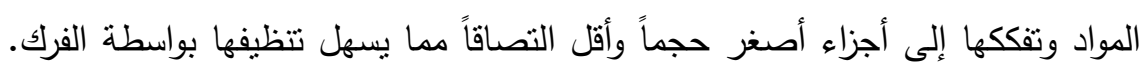
ومن مهام وحدة النظافة بمنشأة رعاية صحية:

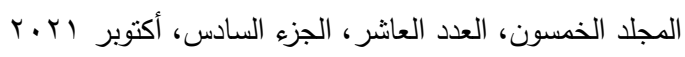

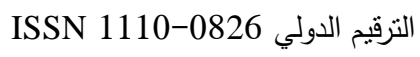

$$
\begin{aligned}
& \text { التزقيم الدولي الموحد الإلكتروني 3178-2636 }
\end{aligned}
$$


التنظيف اليومي: ويشمل أعمال الكس والمسح للأرضيات، وإزالة الأتربة من الأثاث

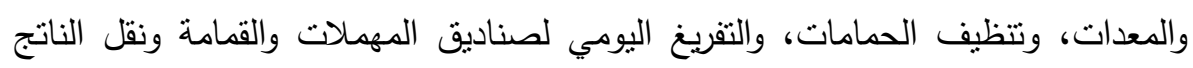

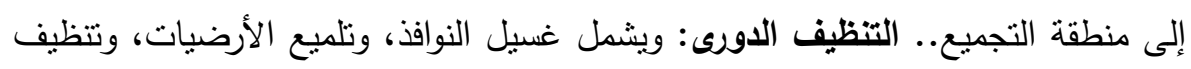

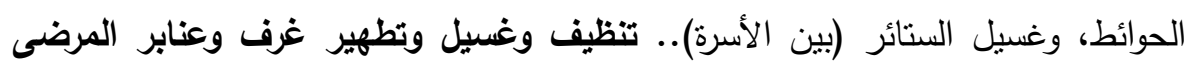

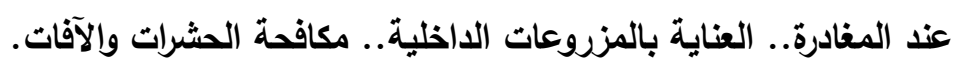

11 - 1 وحدة التطهير: تختص بأعمال النطهير من بعد النظافة فى الأماكن وأدوات

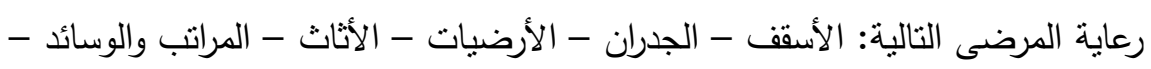

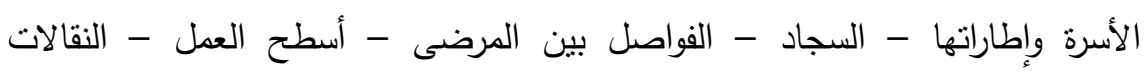

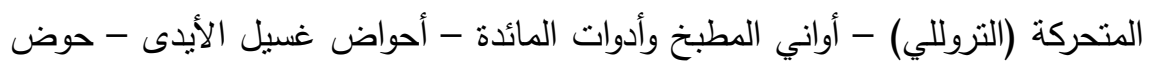

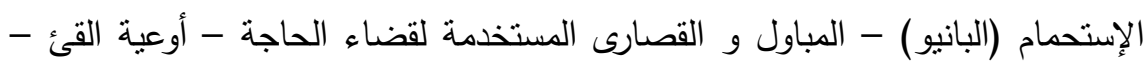

$$
\text { المراحيض وقواعدها - البالوعات - سلال النفايات. }
$$

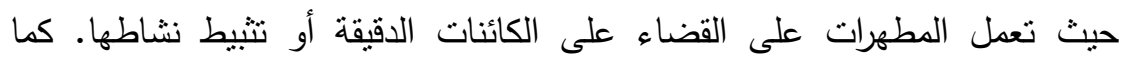

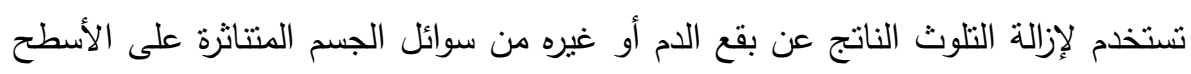

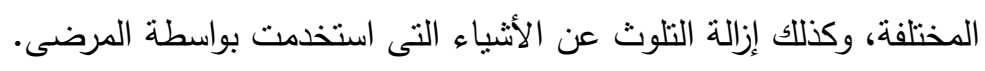

r ا I - وحدة التعقيم: نختص وحدة التعقيم ( (Sterile Supply Unite (SSU) بمعالجة - أى النتظيف، النظهير، النعقيم - الالآت والأدوات والمعدات النقات الطبية المستخمة بالمنثئة الصحية. rا - وحدة المحرقة للنفايات الطبية الخطرة: تختص بالنخلص من المخلفات

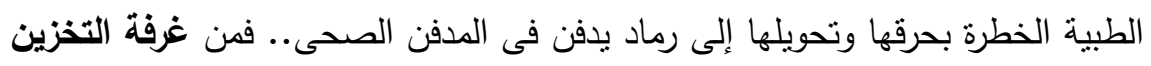

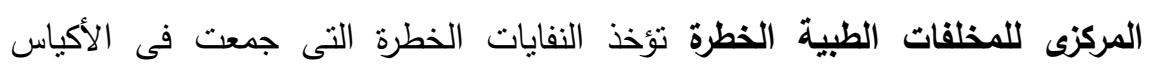
الحمراء من الأقسام الطبية المختلفة بالمستشفى لتفرم ثم تحرق فى المحرقة.

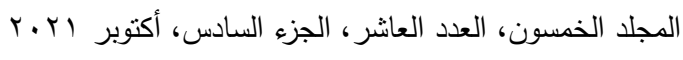

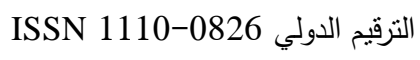

$$
\begin{aligned}
& \text { التزقيم الدولي الموحد الإلكتروني 3178-0826-2636 }
\end{aligned}
$$


؛ أ - وحدة المحطة الوسيطة للمخلفات الصلبة العادية: تختص بالتعامل مع المخلفات الصلبة العادية المتولدة من منثآت الرعاية الصحية فتعالج معالجة النفايات المنزلية والبلدية من حيث الفرز والتصنيف والتدوير وإعادة الاستخدام ....الخ. 10 - وحدة المدفن الصحى: تختص بالتخلص النهائى من المخلفات الطبية الصلبة

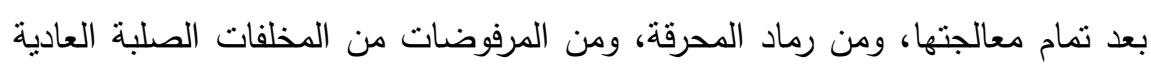

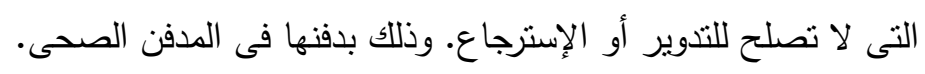

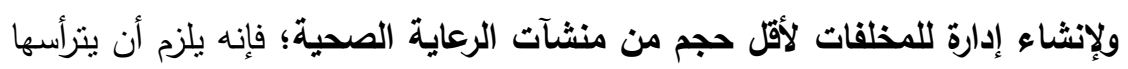

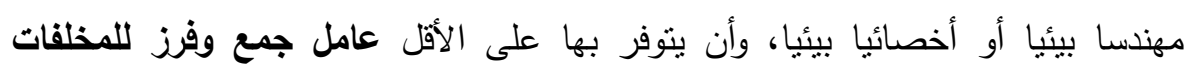

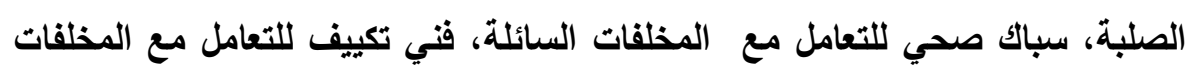
الغازية.

نستتنج مما سبق؛ أصبح من الضرورى إنثاء إدارة تختص بالتعامل مع المخلفات بكافة

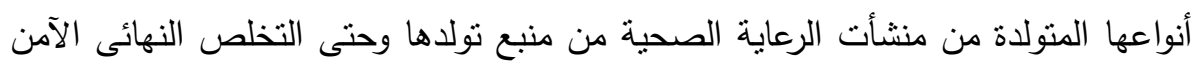

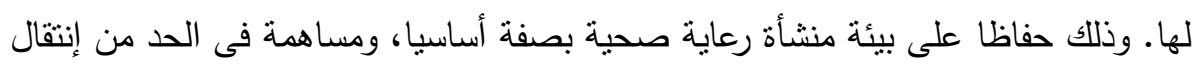

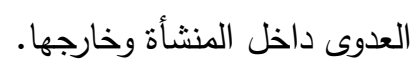

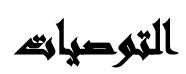

نوصي وزارة الصحة بضرورة تبنى هذا التوجه والأخذ به وتطبيقه على منشآت الرعاية

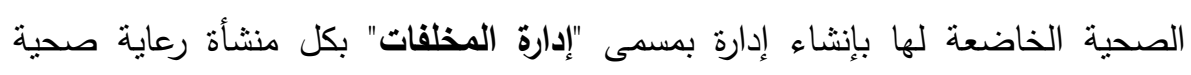

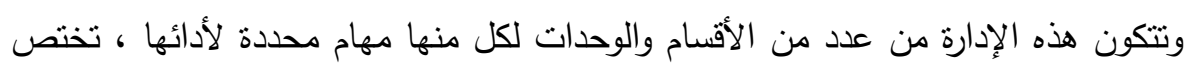

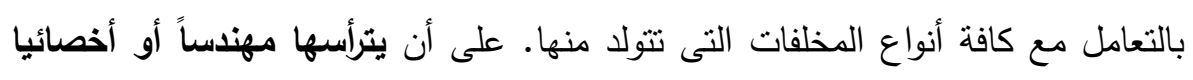

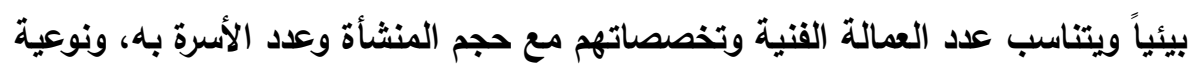

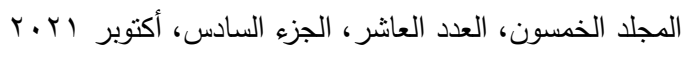

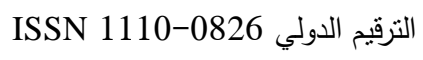

$$
\begin{aligned}
& \text { الترقيم الدولي الموحد الإلكتروني 3178-2636 }
\end{aligned}
$$


الخذات الطبية التى تقدمها للمرضى. وكنلك نوصى بهذا الأقتراح للمسئولين عن إدارة

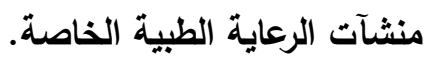

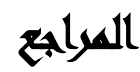

وزارة الصحة والسكان، القطاع الوقائي، الدليل القومي لمكافحة العدوى، جزأن ، الإصدار

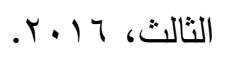

وزارة البيئة، البرنامج الوطنى لإدارة المخلفات الصلبة NSWMP، إدادارة نفايات الرعاية

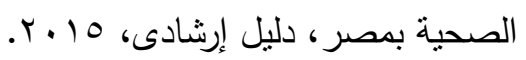

وزارة الإسكان والمرافق والمجتمعات العمرانية، مركز بحوث الإسكان والبناء، الكود المصرى

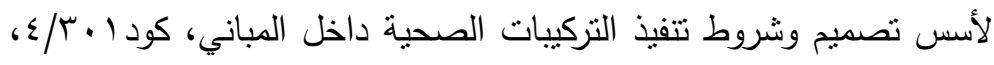

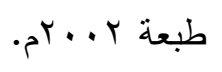

وزارة الإسكان والمرافق والمجتمعات العمرانية، مركز بحوث الإسكان والبناء، الكود المصرى

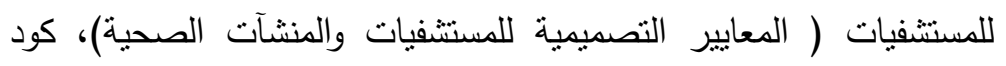

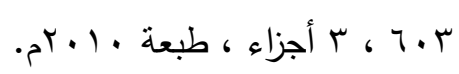

وزارة الإنكان والمرافق والمجتمعات العررانية، مركز بحوث الإنكان والبناء، ندوة الدليل

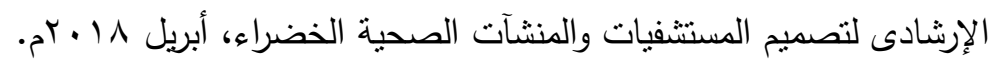

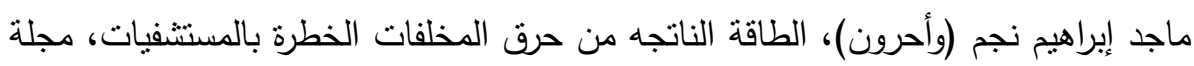

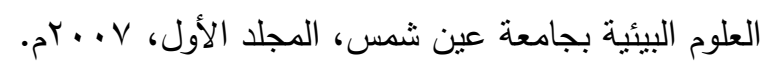

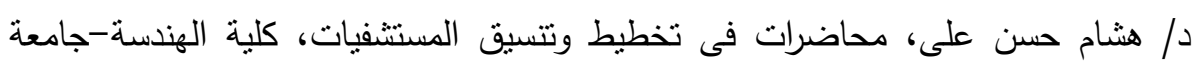

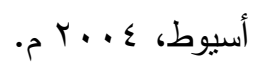

طه حسين فروان وآخرون، برمجة مشروع مستشفى عام سعة ... سرير، كلية الهندسة

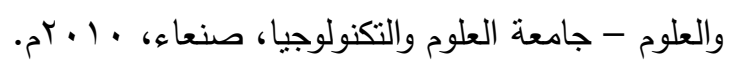

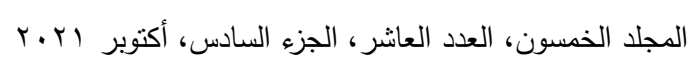

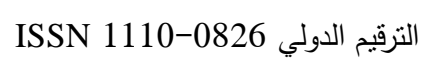

$$
\text { التزقيم الدولي الموحد الإلكتروني 3178-2636 - 2635 }
$$




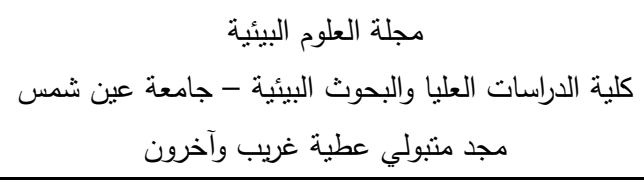

\title{
WASTE MANAGEMENT AND INFECTION \\ CONTROL IN HEALTH CARE ORGANIZATIONS. STRATEGIES
}

\author{
Magd M. Gharib ${ }^{(1)}$; Gamal M. Elkhouly ${ }^{(2)}$; \\ and Mahmoud S. Bokhary ${ }^{(3)}$
}

1) Dar ELMAGD for Engineering Studies and Researches

2) Architectural Dep, Faculty of Engineering, Ain Shams University

3) Faculty of Graduate Studies and Environmental Research, Ain Shams University.

\begin{abstract} their two kinds ordinary and medical from source to their ends for purpose to minimizing infection transfer in health care facilities. waste in health care facilities. it may be consist of the following departments and unites: solid waste dep., liquid waste dep., gas waste dep., pathology waste dep., bacterial waste dep., radiant waste dep., chemicals and drugs' waste dep.,

636

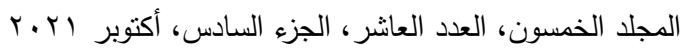

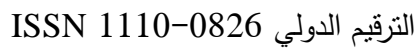

$$
\begin{aligned}
& \text { التزقيم الدولي الموحد الإلكتروني 3178-2636 }
\end{aligned}
$$

The research studies the problem of solid, liquid and gas waste with

The research suggests new concept to establish in the organization chart special central department to manage efficiency all kinds of

To establish a central waste department in large health care facilities 


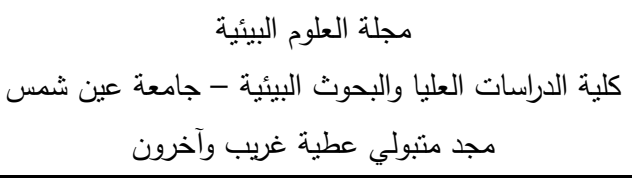

treatment waste unit, rubbish unit, clean unit, disinfectant unit, sterile unit, incineration unit, waste sorting station unit, land fill unit.

To establish a waste department in small health care facilities it must formed from an environmental engineer or specialist as a head and the following workers: worker for collection solid waste, plumber for liquid waste, air-condition technician for gas waste.

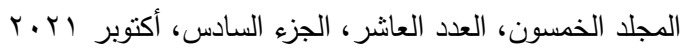

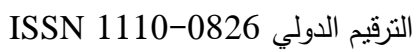

$$
\begin{aligned}
& \text { الترقيم الدولي الموحد الإلكتروني 3178-2636 }
\end{aligned}
$$

